\title{
An Applications Guide to Vehicle SNM Monitors
}

\author{
Paul E. Fehlau
}

\section{DISCLAMMER}

\begin{abstract}
This repont Government. Neither the United States Government nor any agency thereof, nor any of their
employees, makes any warranty, express or implied, or assumed
bility for the accuracy, comploted the United States process disclosed, or reprempleteness, or usefulness of any ines any legal liability or responsience herein to any specific commat its use would not infringermation, apparatus, product, or manufacturer, or otherwise does not product, process, or service by owned rights. Refermendation, or favoring by the United necessarily constitute or imply its endere, trademark, United States of authors expressed htates Governtnent or any agencydorsement, recomUnited States Government or any agein do not necessarily agency thereof. The views
\end{abstract}




\section{CONTENTS}

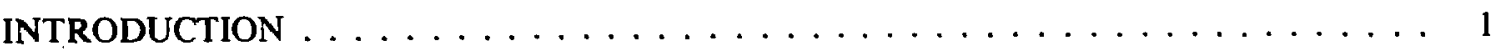

Part 1. AN OVERVIEW OF VEHICLE SNM MONITORING . . . . . . . . . . . . . 1

I. VEHICLE SNM MONITORING $\ldots \ldots \ldots \ldots \ldots \ldots \ldots \ldots \ldots \ldots$

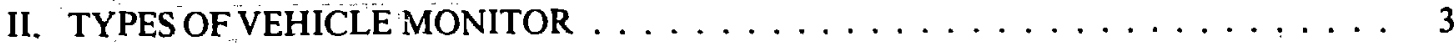
A. Vehicle Portal Monitors . . . . . . . . . . . . . . . . . 3
B. Hand-Held Monitors. . . . . . . . . . . . . . . . . . . 4

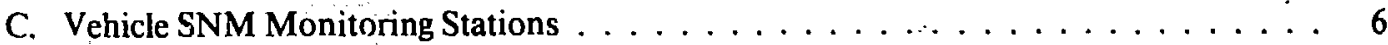
D. Neutron Vehicle Monitors. . . . . . . . . . . . . . . . . 7

III. FACTORS THAT AFFECT VEHICLE SNM MONITOR PERFORMANCE . . . . . . . 7
A. Radiątion Intensity . . . . . . . . . . . . . . . . . 7

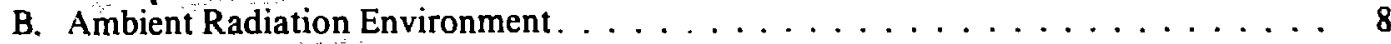
C. Types of Radiation Detector. . . . . . . . . . . . . . . . . . 8
D. Monitoring Measurements and Comparisons . . . . . . . . . . . . 8
E. The Influence of Vehicle Size and Construction . . . . . . . . . . . . . 9
F. The Influence of Vehicle Speed $\ldots \ldots \ldots \ldots \ldots \ldots \ldots \ldots$

IV. EXAMPLES OF VEHICLE SNM MONITOR DETECTION SENSITIVITY $\ldots \ldots \ldots$

V. APPLYING VEHICLE SNM MONITORING TECHNOLOGY $\ldots \ldots \ldots \ldots \ldots \ldots$

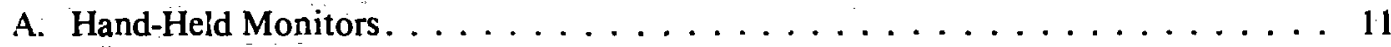

1. Applications . . . . . . . . . . . . . . . 11

2. Testing ......................... 11

B. Vehicle Portal Monitors . . . . . . . . . . . . . . . . 11

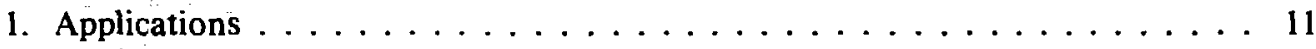

2. Testing ........................... 13

C. Vehicle Monitoring Stations. . . . . . . . . . . . . . . 14

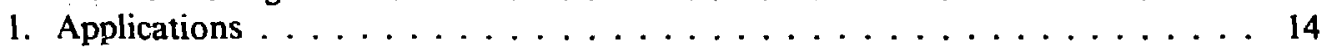

2. Testing ......................... 15

VI. COSTS OF SNM VEHICLE MONITORS $\ldots \ldots \ldots \ldots \ldots \ldots \ldots \ldots$

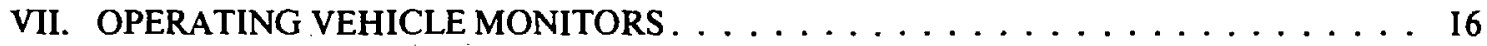

VIII. CALIBRATION AND MAINTENANCE $\ldots \ldots \ldots \ldots \ldots \ldots \ldots$

Part 2. TECHNICAL ASPECTS OF VEHICLE SNM MONITORING. . . . . . . . . . . 18

I. DETECTING SHIELDED SNM IN VEHICLES $\ldots \ldots \ldots \ldots \ldots \ldots \ldots \ldots$

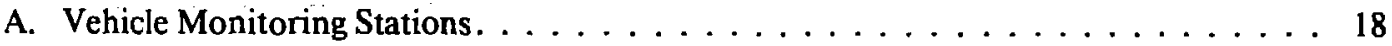

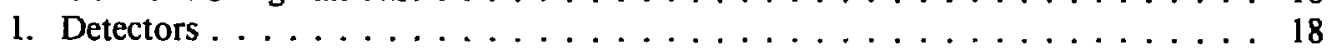

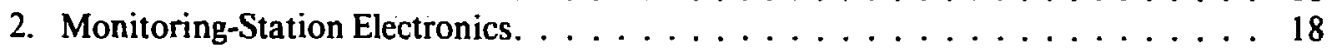

3. Monitoring-Station Performance. . . . . . . . . . . . . . . . . 20

B. Neutron Detection in Vehicle Portal Monitors . . . . . . . . . . . . . 21

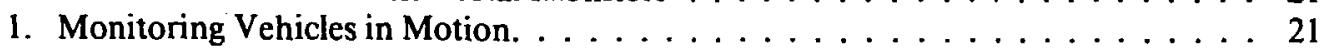

2. Neutron Proportional Counters . . . . . . . . . . . . . . . . . 22

a. A Neutron Chamber Portal Monitor . . . . . . . . . . . . . . . . . 23

b. A Neutron Slab Portal Monitor . . . . . . . . . . . . . . . . . . . . 23

3. A Prototype Neutron Vehicle Portal Monitor. . . . . . . . . . . . . . . . . 24 


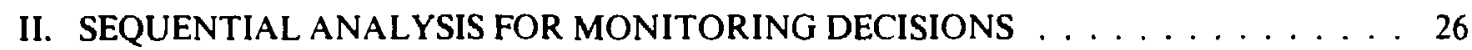

III. HAND-HELD MONITORS WITH NEUTRON SENSITIVITY . . . . . . . . . . . 27

Part 3. A CATALOG OF VEHICle SNM RADIATION MONITORS . . . . . . . . . . . . 29

I. HAND-HELD VEHICLE SNM RADIATION MONITORS . . . . . . . . . . . 30

II. TSA SYSTEMS VM 106 VEHICLE PORTAL MONITOR . . . . . . . . . . 31

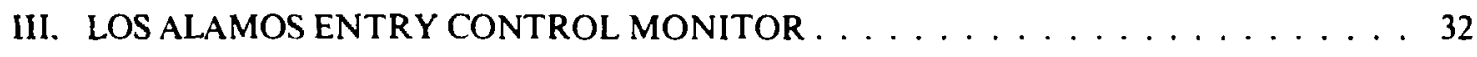

IV. LOS ALAMOS VEHICLE SNM PORTAL MONITOR. . . . . . . . . . . . 33

V. TSA SYSTEMS VMC-250 VEHICLE PORTAL MONITOR. . . . . . . . . . . . . . 34

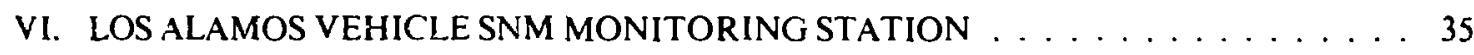

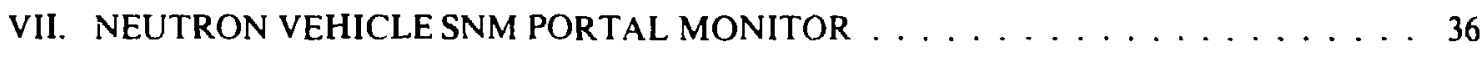

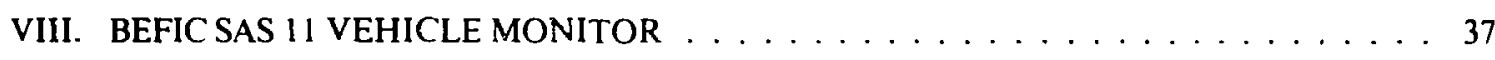
ACKNOWLEDGMENTS ....................... 38

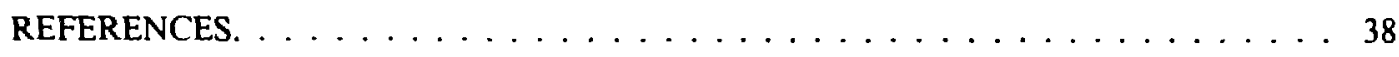




\title{
AN APPLICATIONS GUIDE TO VEHICLE SNM MONITORS
}

\author{
by
}

Paul E. Fehlau

\begin{abstract}
The applications guide introduces its readers to the vehicle special nuclear material (SNM) monitors that are becoming part of safeguards and security measures for nuclear material control at DOE facilities. Building on the foundation provided by an applications guide to pedestrian SNM monitors published in 1986 and a technical report on vehicle monitoring published in 1982, the guide provides an overview of vehicle monitoring in Part 1 , a discussion of technical aspects of vehicle monitoring in Part 2, and a catalog of vehicle SNM monitors available to DOE facilities in Part 3. Vehicle monitor upkeep, calibration, testing, and performance are important topics in Part 1. The short technical discussion in Part 2 is devoted to new developments and unique features of vehicle monitors.
\end{abstract}

\section{INTRODUCTION}

Although vehicle special nuclear material (SNM) monitoring has been used for nuclear materials control since 1974 , only recently have highly effective monitors been developed, become commercially available, and found their way into routine use. The monitors offer an effective means to search vehicles for SNM with minimum delay by sensing the specitic indication of SNM presence provided by its gamma-ray and neutron radiation.

Vehicle monitors are less familiar to us than pedestrian SNM monitors because we most often enter SNM access areas on foot. But vehicle entry points to SNM access areas are monitored as are some vehicle entry points to protected are $\varepsilon$.. In addition, some facility entry roads are monitored as a means to further control the movement of SNM or radioactive material. This guide is designed to familiarize you with the different types of vehicle monitors and the ways that they can appropriately be used.

We have organized the guide into three sections to cover specific areas of interest. Part 1 is a general overview of vehicle monitoring that describes the monitors and their applications and then discusses operating, testing, and maintaining the monitors. Part 2 provides a technical discussion of neutron and gammaray vehicle monitor developments since 1982 . Part 3 catalogs the commercially available vehicle monitors.

\section{PART 1}

\section{AN OVERVIEW OF VEHICLE SNM MONITORING}

\section{VEHICLE SNM MONITORING}

Many DOE facilities have security plans that require searching vehicles for SNM as they depart SNM access areas or protected areas. Detecting gamma-ray and neutron radiation from SNM provides an effective and convenient means to search for SNM in vehicles. An SNM vehicle monitor is an intelligent radiation detection system whose actions to detect SNM are illustrated by the flow chart in Fig. 1; to detect SNM, the monitor senses a radiation intensity increase by comparing its monitoring measurements with an alarm threshold derived from previous unoccupied background measurements. The monitoring method is somewhat different in each of the three types of vehicle SNM monitors, simple hand-held units, vehicle portals, and vehicle monitoring stations that are illustrated in the collage (Fig. 2). The 


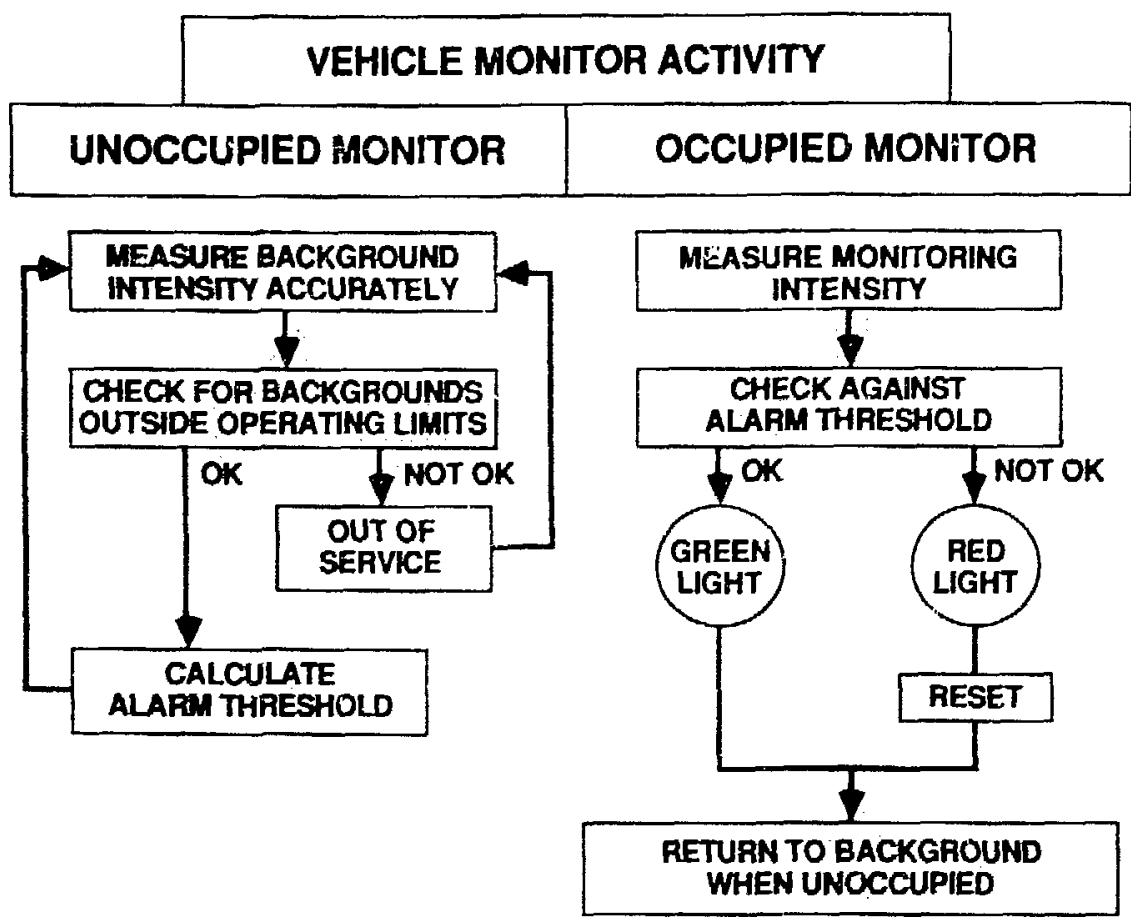

Fig. 1. A vehicle monitor measures background intensity when unoccupied. When a vehicle is sensed, monitoring begins.

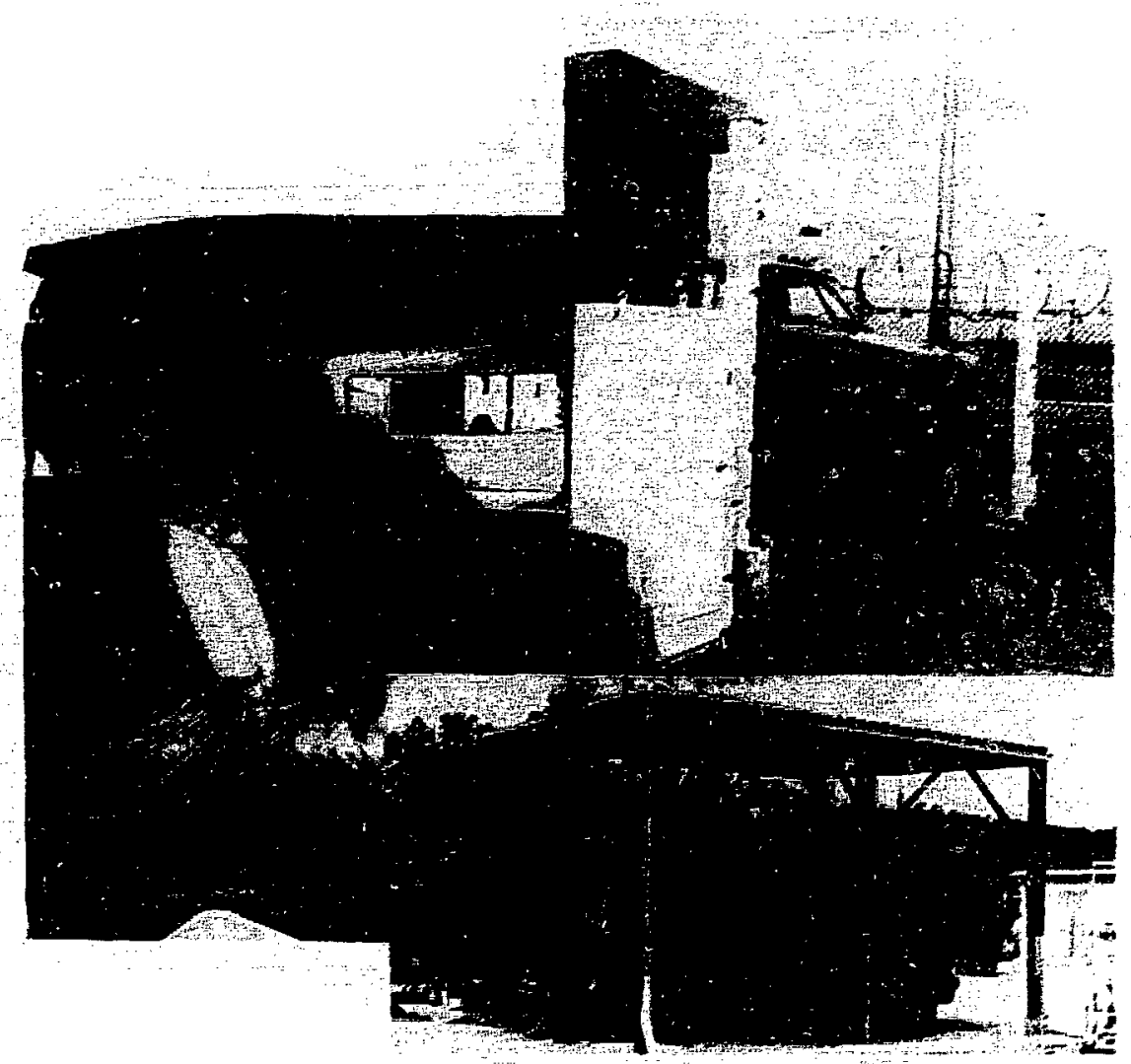

Fis. 2. Vehicle SNM monitors range from small hand-operated units to automatic drive-through, vehicle SNM portal monitors and vehicle SNM monitoring stations. 
detectors and detection methods used in the monitors make each of them suitable for particular monitoring tasks.

The following pages describe vehicle monitors and discuss monitoring procedures. A word of caution on interpreting our discussion of sensitivity estimates for the monitors is in order. We have made worst-case sensitivity estimates for the monitors so that better performance will always be obtained under routine circumstances. We achieved the worst case by using SNM in a form having maximum self-absorption of its radiation and with an isotopic content that produces minimum radiation intensity. Routinely encountered SNM will emit more radiation. We also use moderately radiation-opaque vehicles that absorb both SNM and environmental radiation. Finally, our background intensity is $20 \mu \mathrm{R} / \mathrm{h}$, a value that exceeds routine environmental values.

Procedures for monitoring vehicles for SNM are significantly different from those for monitoring pedestrians; hence, this guide is a necessary companion to the pedestrian SNM monitor guide.' Although the basic science is much the same for pedestrian and vehicle monitoring, the large size of motor vehicles and the fact that vehicles are constructed from radiation-attenuating materials make highly effective vehicle monitoring more difficult to achieve. This guide summarizes basic information ${ }^{1,2}$ on monitoring and concentrates on vehicle monitor applications. For example, basic information on the properties of SNM radiation is summarized before discussing the influence that vehicles have on that radiation.

Just as for pedestrians, two distinct types of monitor are used to monitor vehicles, hand-held and fully automatic. The two types have important differences as wel! as similarities in the way they are used. For example, hand-held monitors differ from automatic monitors in the operator's important contribution to effectiveness. An effective search with a hand-held monitor requires careful scanning throughout a vehicle's interior ano over its entire exterior, bringing the detector as close as 2 to 6 in. ( 5 to $15 \mathrm{~cm}$ ) to any object that may contain SNM (Ref. 3). Hence, effective hand-held monitoring requires an operator who is well trained, is properiy motivated and supervised, and has adequate time for a thorough search.

Automatic vehicle monitoring systems search vehicles with little assistance; a visual check by the operator for proper vehicle position in the monitor may be necessary, and periodic maintenance and testing are regular requirements. Although automatic monitors are initially more expensive, they have low operational costs. The overall cost for a period of years may not exceed that of the equally effective hand-held monitor.

A similarity between the two types of monitor is that they require periodic upkeep. Daily checks with radioac- tive material are important to make sure that an occupied monitor alarms when radiation intensity increases. Small radioactive sources placed near each detector should cause an alarm; if all detectors in a monitor are not checked each day, they should be checked in a cycle that covers all detectors within a few days. The daily source check assures continuity of all monitoring circuits between radintion detection and alarm announcement; any serious flaw is immediately noticed. The occupancy sensors for automatic monitors also must be checked daily to assure operation; this check may be incidental to a normal vehicle passage through the monitor. The hand-held monitoring technique should also be observed daily to assure that it is effective. $^{3}$

Longer-term testing of monitors also is necessary to make sure that the monitors are properly calibrated. At least once per quarter ( 3 months), each monitor should be checked by electronic maintenance technicians and recalibrated if necessary. Then its performance should be tested with SNM or an alternative radioactive test source. This test will reveal whether the most effective operation of the monitor is being obtained. As with daily tests, good record keeping of all calibration parameters and test results will later help to analyze possible operating problems and also will provide evidence of a well-run maintenance program.

\section{TYPES OF VEHICLE MONITOR}

\section{A. Vehicle Portal Monitors}

The elements of a vehicle SNM monitor are illustrated by the vehicle portal monitor sketched in Fig. 3, which is similar to the familiar walk-through pedestrian monitor. This vehicle portal monitor is located in a vehicle trap, a segment of single-lane roadway with perimeter fencing and electrically operated gates at each end. As a vehicle enters the trap, it slowly moves through the vehicle portal's radiation detectors, which are large plastic scintillation detecrors housed in weathertight cabinets beside the roadway. The detectors are sensitive to both gamma rays and neutrons, the most penetrating forms of SNM radiation. Detector signals from both sides of the roadway are summed and analyzed together to obtain maximum sensitivity at the vehicle center. For wider roadways having two lanes, independently analyzing signals from each side of the roadway, no matter which lane is occupied, may be the more effective approach. In either case, when a vehicle is detected by traffic-sensing elements buried in the roadway, background observations are suspended and monitoring begins.

Electronic circuits to condition and analyze the detector signals are located near the detectors and are 


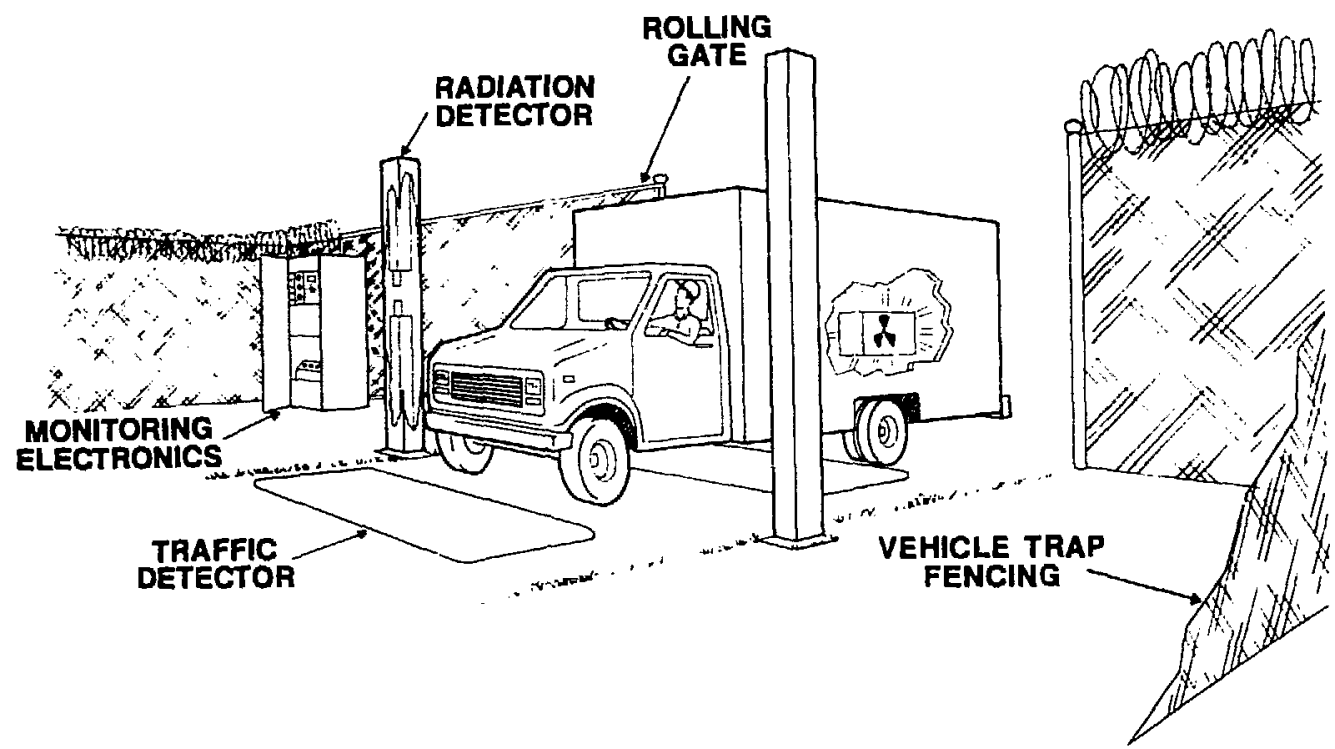

Fig. 3. The basic elements of a vehicle SNM monitor are illustrated by this vehicle portal monitor that monitors vehicles as they slowly pass through the detectors.

housed in a weathertight electronics cabinet. When notified that a vehicle is present, the circuits continuously measure radiation intensity in the monitor and analyze the results with either a sliding interval or a sequential detection method, each of which compares the results of short monitoring measurements with alarm thresholds. For slowly moving vehicles $(8 \mathrm{~km} / \mathrm{h})$ passing between the detectors, as many as five or six separate monitoring decisions may be made, which correspond to separately monitoring each meter of a vehicle's length as it moves through.

The results of monitoring are announced through a remote information module that is normally located in a guard station but shown in Fig. 3 on the lower shelf of the electronics cabinet. The information module provides all the information and control required by the operator. When a significant radiation intensity increase is detected, an alarm sounds. Otherwise, once the vehicle passes beyond the traffic detector, monitoring ceases and the vehicle monitor resumes background observation. Then the operator can open the exterior gate and allow the vehicle to depart.

Locating a vehicle portal in a trap is not the only way that vehicle portals are used. Some vehicle portal monitors are placed beside roadways at a distance from a badge inspection point. This application of a vehicle portal is suitable where large quantities of SNM or very radioactive forms of SNM need to be detected. Bath the wider spacing between the detector cabinets and the possibility of increased vehicle speed decrease the vehicle portal's detection sensitivity. In this case, detector signals from each side of the roadway would likely be analyzed separately because center-line sensitivity is not as important as sensitivity in the nearest lane.

\section{B. Hand-Held Monitors}

Although hand-held monitors are small and seem less complex, their elements are the same as those of vehicle portal monitors. Other than in size, they usually differ only in having a sodium iodide [NaI(Tl)] detector instead of a plastic scintillator and a push-button switch for monitoring (occupancy switch) or updating the background (vacancy switch). Figure 4 illustrates interior details of an effective, lightweight, and low-power handheld SNM monitor developed at Los Alamos. The monitor is powered by batteries that must be recharged after about $48 \mathrm{~h}$ of use. The monitor's electronic circuits carry out signal conditioning and analysis functions, and repeated single-interval intensity tests detect SNM. The monitor has a relatively low alarm threshold because a high rate of statistical false alarms does not interfere with hand monitoring; repeated alarms at a particular location detect SNM. Most hand-held monitors operate continuously unless the operator presses a background reset button to obtain a new background value. The operator updates the background guided by the operating procedure in Ref. 3, which uses statistical false alarms to judge when to update.

The key to effective hand-held monitoring is getting the radiation detector close to all locations where SNM may be hidden. The small radiation detector is highly effective when it is close to SNM. Hence, the operator must move the monitor throughout the vehicle interior and over its exterior, being sure to get close to all possible locations for SNM. He is guided by the instrument's audible chirps when it senses a radiation intensity increase. The instrument should sound random chirps from time to time; these usually correspond to 


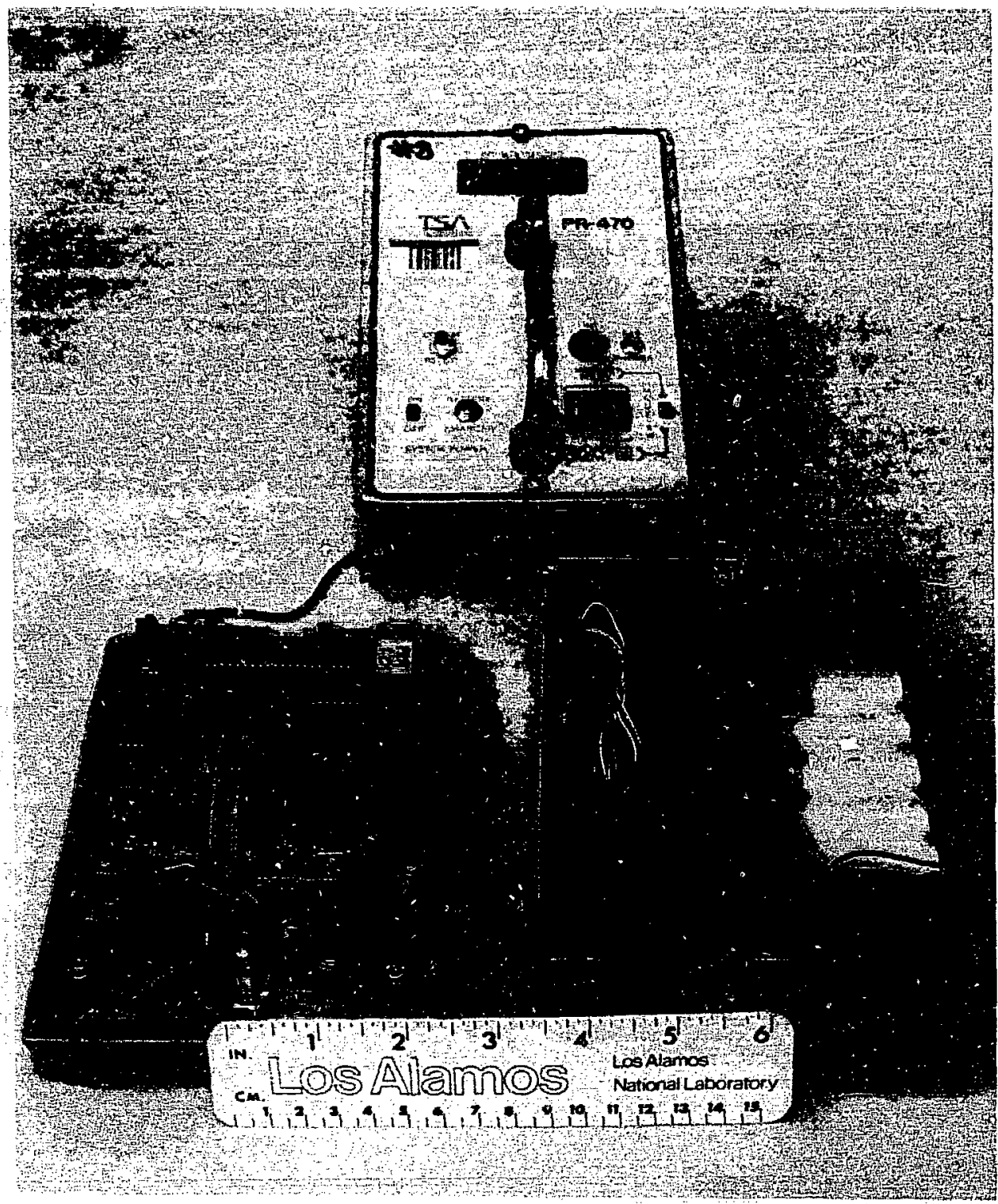

Fig. 4. A lightweight hand-held monitor has the same basic elements as other vehicle SNM monitors. The radiation detector and microprocessor electronics are operated by rechargeable batteries.

statistical increases, but they can also be caused by real intensity increases. The operator locates SNM by finding places where the monitor chirps continuously and repeats the chirping when the monitor moves away and then back to the same place.

Hand-held instruments with $\mathrm{NaI}(\mathrm{Tl})$ scintillators have lower neutron sensitivity than do automatic monitors with plastic scintillation detectors, a characteristic which makes it difficult for them to detect heavily shielded plutonium. But, the $\mathrm{NaI}(\mathrm{Tl})$ scintillators make hand-held monitors lighter, less bulky, and easy to use continuously. Plastic scintillation detectors are generally heavier than $\mathrm{NaI}(\mathrm{Tl})$. One hand-held monitor with a plastic scintillation detector, the TSA Systems* HHD-440 monitor described in Part 3, weighs $3 \mathrm{~kg}$ (6.6 lb), almost three times as much as the lightweight monitor in Fig. 4 (which is also available from TSA Systems as the PRM-470). However, the HHD-440 has

-TSA Systems, Inc., 4919 North Broadway, Boulder, CO $80302_{2}(303)$ 477-8553. 
good neutron sensitivity in addition to detecting gamma rays. It can detect a particular plutonium sample inside lead shielding 2 in. thick, too thick for $\mathrm{NaI}(\mathrm{Tl})$ handheld monitors to do so. The HHD-440 would be more useful for plutonium areas if it were lighter. Los Alamos has recently adapted a lightweight plastic scintillator to a PRM-470, increasing its weight from $1.1 \mathrm{~kg}(2.4 \mathrm{lb})$ to $1.6 \mathrm{~kg}$ ( $3.5 \mathrm{lb}$ ), about half the weight of the HHD-440.

\section{Vehicle SNM Monitoring Stations}

Neither vehicles nor detectors move during monitoring in a vehicle monitoring station (Fig. 5). The monitoring station has groups of detectors positioned around a parked vehicle and achieves high sensitivity by separately analyzing the measurements from each group during a relatively long monitoring period. The threeview sketch of a monitoring station (Fig. 6) shows the aluminum-covered trenches in the roadway that each contain two large plastic scintillation detectors. Each pair of trenches (four detectors) is a detector group whose measurements are separately analyzed; in fact, each detector group is an independent monitor. There are three underground detector groups and an addi- tional one overhead that is supported from the canopy. The three underground detector groups are very close to the vehicle and are well spread out to view around the vehicle or its cortents. From above, there is little to obscure the view and the single detector group suffices. The overhead group easily senses SNM that might be placed on top of the vehicle's cargo.

The vehicle monitoring station in Fig. 6 is the most effective for general use. Vertically oriented detectors at the sides can be added to monitor vehicles from additional directions, but these detectors are incrementally less effective than the ones located above and below the vehicle. Additional side-mounted detectors can overcome specific shortcomings, perhaps caused by a unique vehicle type; side-mounted detectors are effective only when some aspect of a vehicle provides shielding from both above and below.

In operation, a vehicle monitoring station senses an entering vehicle with detectors placed in the roadway; it waits a few seconds to allow the vehicle to park and then begins monitoring. Each detector group provides signals to separate signal-conditioning and analysis circuits, and each analysis circuit makes an independent monitoring decision. A single decision that SNM is present causes an alarm. On the other hand, all four groups must

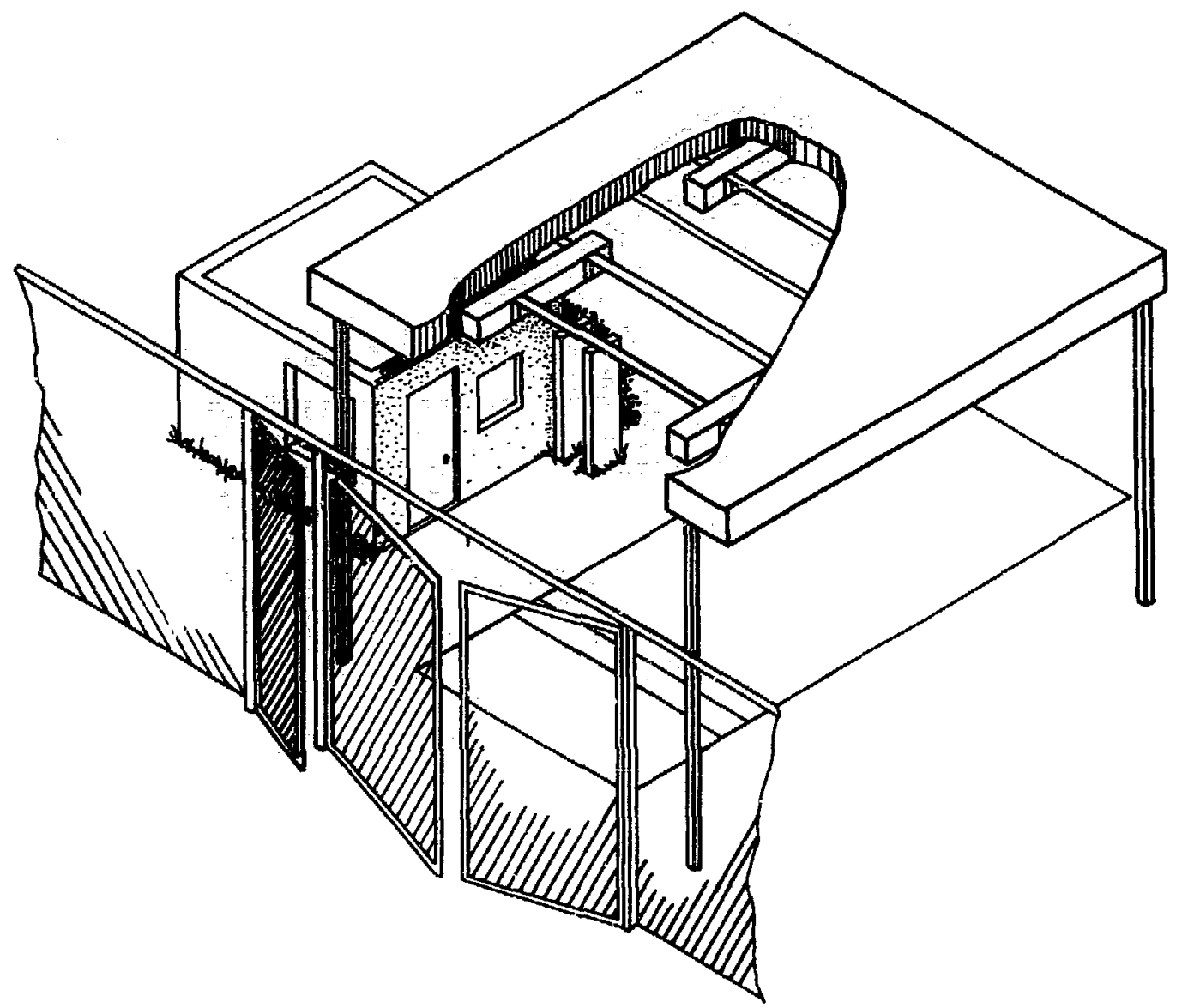

Fig- 5. The vehicle SNM monitoring station monitors stationary vehicles to obtain the highest sensitivity. 

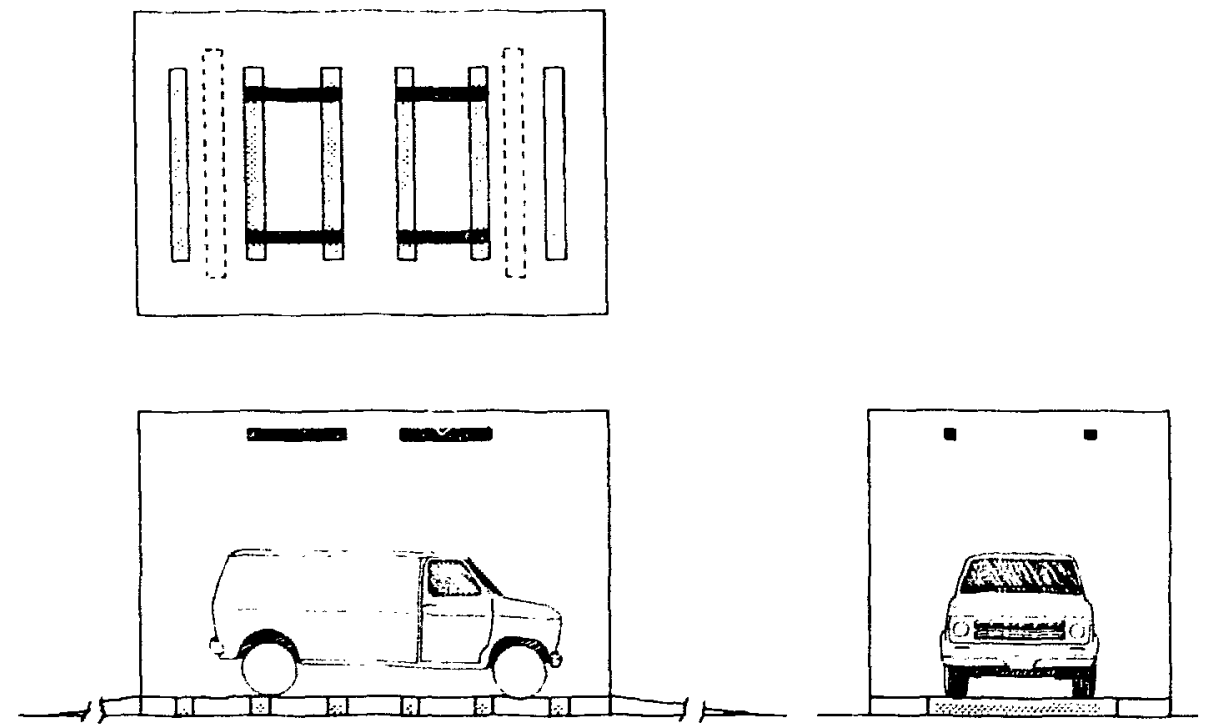

Fig. 6. These orthoganal views of the Los Alamos vehicle SNM monitoring station illustrate the detector cabinet positions. Underground detector cabinets are in trenches covered by aluminum diamond plate.

reach decisions that no SNM is present to complete monitoring and clear a vehicle for departure.

The method used for decision analysis in a monitoring station is a sequential hypothesis test that makes a sequence of short monitoring measurements and has separate decision thresholds for background or alarm outcomes. After each short measurement in the monitoring sequence, if neither a background nor an alarm decision can be made, monitoring continues with another short measurement until a maximum total monitoring time is reached, perhaps at $1 \mathrm{~min}$. The consensus background outcome is quickly reached when no radioactive material is present; a rapid alarm decision also is reached when a strong source of radiation is present. However, SNM signals just at the threshold for detection may require a full minute to detect. On the average, routine traffic carrying no radioactive material experiences a monitoring delay of only aboui $20 \mathrm{~s}$ when the maximum allowed time is $1 \mathrm{~min}$.

\section{Neutron Vehicle Monitors}

Neutron sensitivity is desirable in a vehicle SNM monitor at a plutonium facility to maintain a minimum level of sensitivity for plutonium that may be heavily shielded to attenuate gamma rays, the principal radiation emitted by plutonium. Vehicle monitors using plastic scintillation detectors are sensitive to neutrons in addition to gamma rays although the gamma-ray background limits their effectiveness as neutron detectors. The limitation is serious only in vehicle portals where the detectors are few and far from the SNM. A vehicle monitoring station is less affected; for example, under worst-case conditions (Part 1.I, paragraph 2), it senses less than a gram of low-burnup plutonium by gammaray detection and $250 \mathrm{~g}$ by neutron detection.

The limited sensitivity of vehicle portals for detecting gamma-ray shielded plutonium is improved with neutron proportional counter detectors that have no gamma-ray sensitivity. These neutron detectors are more expensive than gamma-ray detectors and by themselves do not detect highly enriched uranium (HEU) and other gamma-ray emitting materials that emit very few neutrons. Hence, neutron portals are not commercially available in this country although neutron monitors have been demonstrated here. ${ }^{2}$ Two pedestrian portals are commercially available in foreign countries to protect forms of plutonium that emi: many neuirons. The technical aspects of neutron monitoring and a newly developed neutron vehicle portal monitor are discussed in Part 2.

\section{FACTORS THAT AFFECT VEHICLE SNM MONITOR PERFORMANCE}

The most important factors that affect vehicle SNM monitor performance are the SNM radiation intensity, the monitor's ambient background intensity, the placement and type of radiation detectors, the monitoring method, and the size of the vehicle being monitored.

\section{A. Radiation Intensity}

SNM radiation is described in Ref. 1 . One of the most important points about SNM radiation discussed there 
is the different character of the radiation emitted by the two common forms of SNM, low-burnup plutonium and HEU. Plutonium emits much more radiation per gram of material (higher specific activity) than does HEU and emits both gamma rays and neutrons, whereas HEU is primarily a gamma-ray emitter. Hence, plutonium is detectable in smaller quantities than is HEU. Not only does plutonium emit more gamma rays, but some of its gamma rays are more penetrating, and these, together with its neutron emission, make it possible to detect plutonium inside gamma-in: shielding.

Forms of SNM other than low-burnup plutonium and HEU may contain particular isotopes that significantly influence radiation output. For example, low-burnup plutonium has only about $6 \%$ of the isotope ${ }^{240} \mathrm{Pu}$, which is the source of its neutron emission, whereas reactorgrade plutonium may have $12 \%$ or more ${ }^{240} \mathrm{Pu}$ and emit many more neutrons. Along with a high ${ }^{240} \mathrm{Pu}$ content is usually a high ${ }^{241} \mathrm{Pu}$ content, an isotope responsible for time variable gamma-radiation emission; as ${ }^{241} \mathrm{Pu}$ decays, the daughter, ${ }^{24} \mathrm{Am}$, a prolific gamma-ray emitter, builds up. The gradual build up of ${ }^{241} \mathrm{Am}$ makes plutonium a poor reference material for gauging SNM monitor performance. Uranium also can be a prolific gamma-ray emitter if it contains significant amounts of ${ }^{232} \mathrm{U}$, but this is relatively uncommon. Highly enriched uranium has very little variation in its radiation emission and is a good test material for SNM monitors.

The physical form of SNM influences the amount of self-absorption of its radiation. Powdered material, foils, shavings, and other thin forms can emit up to 10 times as much radiation as the same quantities of bulk material that reabsorbs up to $90 \%$ of its own gamma-ray emissions. On the other hand, neutron-emitting materials usually have little self-absorption. Besides self-absorption, radiation can be absorbed in external shielding materials. Reference 2 , p. 8 , contains a discussion of the influence of varying thicknesses of external shielding on SNM radiation intensity.

Other information on radiation from specific types of SNM can be found in Refs. 4 and 5.

\section{B. Ambient Radiation Environment}

A changing radiation environment can affect radiation monitor performance. During monitoring, an increase in background intensity can be misinterpreted by a vehicle monitor and cause an alarm, or a decrease in intensity may mask an SNM signal. Hence, monitors should be located in places where the ambient radiation background is relatively s::ady. When large background variation cannot be avoided, hand-held monitoring may be the best method to use for monitoring because the hand-held monitor background can be quickly up- dated when necessary and because its performance is less affected by small changes in background. Aiso, a few random alarms during hand-held monitoring are not significant; only local regions having high chirp rates indicate SNM. On the other hand, automatic monitors attach high significance to every alarm, and they take longer to update background and must be unoccupied to do so.

In addition to variability, the magnitude of the background intensity influences SNM monitor performance.

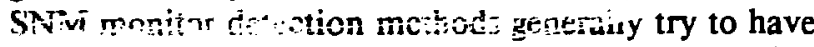
the same false-alarm rate at any background intensity. As a result, sensitivity lessens as the background intensity increases (Ref. 1, Part 2). There is not much we can do about the large regional differences in background intensity around the US, but we can often limit the influence of a facility's own activities on background by locating monitors at a distance from process materials where sensitivity will be better and interference less likely.

\section{Types of Radiation Detector}

Previously we mentioned that plastic scintillators detect both gamma rays and neutrons, making them ideal for detecting plutonium, bare or shielded. Other neutron detectors such as ${ }^{3} \mathrm{He}$ or $\mathrm{BF}_{3}$ proportional counters have negligible gamma-ray sensitivity but easily detect neutron sources in neutron background intensities that are usually very low. The relative merit of the two types of neutron detector is further discussed in Part 2.

Uranium monitoring seldom involves neutron detection; only fluorine compounds of uranium emit many neutrons. Therefore, for monitoring HEU, $\mathrm{NaI}(\mathrm{Tl})$ detectors are effective. However, the high cost of $\mathrm{NaI}(\mathrm{Tl})$ makes it less economical for monitoring vehicles, particularly in monitoring stations where large detector areas are needed. We most often find plastic scintillation detectors in automatic vehicle inonitors. The two types of detector, $\mathrm{NaI}(\mathrm{Tl})$ and plastic scintillators, are described and compared in Ref. 1, Part 2.

Hand-held monitors, on the other hand, are compact instruments that benefit from the light weight and high intririsic detection efficiency of $\mathrm{NaI}(\mathrm{Tl})$. These instruments depend on proximity between SNM and detector for effectiveness; hence, the small, lightweight $\mathrm{NaI}(\mathrm{Ti})$ detectors are a good choice and are most often used.

\section{Monitoring Measuremerts and Comparisons}

The methods used to make radiation intensity measurements can influence the performance of any radiation monitor. For example, SNM is detected by 
sensing a significant increase when one compares the expected radiation intensity in an occupied monitor with the measured value. The sensitivity of such a comparison depends on how precisely the background and monitoring intensities are measured (Ref. 2, Sec. V). High precision requires long measurement times. We try to take advantage of the periods of time when a monitor is unoccupied to establish a precise and timely background, a procedure that is limited only by the time scale of significant background intensity variation.

Monitoring measuremerts, on the other hand, must be relatively short to maintain reasonable traffic flow. Monitoring delays longer than a minute or so are rarely tolerated. Also, short monitoring measurements are less influenced by ambient radiation intensity variation. Even slight var:ation during monitoring may be important; for example, an alarm threshoid four standard deviations above background in a vehicle monitoring station may be only $2 \%$ above background. The likelihood of a false alarm is reduced by the presence of a vehicle in the monitoring station, which depresses the background a few per cent, increasing the signal needed to alarm to $5 \%$ or more (Ref. 2, Sec. II). An improvement in the decision logic for monitoring stations shortens monitoring time with sequential monitoring analysis. A sequence of very short measurements is analyzed, and monitoring ends as soon as a decision meeting sensitivity and false-alarm rate requirements can be made. This method greatly decreases the average monitoring time (Part 2.II). Other types of vehicle monitors, vehicle portals and hand-held monitors, may monitor more rapidly and be less subject to background intensity variation.

Once background and monitoring measurements are made, the way to decide whether they differ significantly will influence both the monitor's detection sensitivity and its statistical false-alarm ratc. Sensitivity and falsealarm rate are closely related as discussed in Ref. 1 , Part 2, and quoting one without the other has little value. We most often choose an alarm threshold that gives a low statistical false-alarm frequency and then accept the resulting sensitivity. Hand-held monitoring is not inconvenienced by occasional statistical alarms, but automatic monitoring treats every alarm as an indication of SNM. Hence, automatic monitor alarm thresholds are set cautiously to avoid nuisance alarms that can lead to lack of confidence in the monitor. Where the amount of traffic through vehicle monitoring stations is relatively low, statistical alarm rates of 1 or more per 1000 passages* can be tolerated, whereas

\footnotetext{
* A passage may include one or many statistical decisions that affect the monitors' false-alarm rate.
}

perhaps only 1 per 4000 passages is acceptable in more active monitors. In each case the result should be less than one statistical alarm a day for typical traffic flow rates.

\section{E. The Influence of Vehicle Size and Construction}

Vehicles influence SNM monitor performance in two ways, both of which can depend on the size of the vehicle. First, the presence of the vehicle reduces the background intensity in the monitor, making it a bit harder to detect SNM. Second, the materials from which the vehicle is constructed provide a certain amount of gamma-ray shielding that reduces the SNM signal intensity. The background influence is fairly regular, but the amount of shielding depends on the position of the SNM in the vehicle. Hence, the performance of a vehicle SNM monitor is quite difficult to predict; it not only depends on such variables as background intensity and SNM type and form but aiso depends significantly on the type of vehicle and SNM location within the vehicle.

A worst-case example of the amount of variability between vehicle types is illustrated in Table 1 . The first column in the table compares the fraction by which a prototype vehicle portal monitor's background is reduced when occupied by a variety of vehicles. The second column shows the fraction of source radiation that is transmitted outside the vehicle when the SNM is in the location in the vehicle where shielding is most effective. The background reductions in the first column certainly become more significant as vehicle size increases. However, the amount of radiation emitted from a vehicle depends more on the type of construction than on the vehicle size. The final column estimates the detection probability for a particular radiation source located in each of the vehicles. The results range from always detecting this particular source to never detecting it; the overall results do not vary directly with size or attenuation but with the combined effect of the two variables. These results show why vehicle portal monitors are usually the least effective type of automatic vehicle monitor. Vehicle monitoring stations are not so greatly affected by vehicle presence and are less affected by shielding; hence, they can be more sensitive. For this reason, vehicle portals are used only where relatively large quantities of SNM need to be safeguarded.

\section{F. The Influence of Vehicle Speed}

Vehicle portals monitor vehicles as they pass through detectors that form the portal. The monitor's detection procedure usually is selected with a particular passage speed in mind. The counting time matches the time 


\begin{tabular}{lccc}
\hline \hline $\begin{array}{l}\text { TABLE I. Reduced } \\
\text { Monitor }\end{array}$ & Backgrounds and Signals in an Occupied Vehicle Portal \\
\hline & $\begin{array}{c}\text { Occupied/Unoccupied } \\
\text { Background Ratio }\end{array}$ & $\begin{array}{c}\text { Transmitted- } \\
\text { Signal Ratio }\end{array}$ & $\begin{array}{c}\text { Detection" } \\
\text { Probability }\end{array}$ \\
\hline Motor Vehicle & 0.94 & $\mathbf{0 . 3 4}$ & 0.995 \\
\hline Japanese pickup & 0.92 & 0.30 & 0.5 \\
American pickup & 0.90 & 0.45 & 1 \\
Carryall & 0.90 & 0.21 & 0 \\
Small van & 0.90 & 0.44 & 1 \\
Large van & 0.78 & 0.58 & 0.684 \\
Secure vehicle & 0.73 & 0.35 & 0 \\
Safe, secure transport & Analyzed for a vehicle portal with background of 3000 counts and net bare source contribu- \\
"tion of 1600 counts per monitoring interval. The source is located in the position with \\
maxinum attenuation in each vehicle.
\end{tabular}

interval that SNM is likely to be close to the detectors. With an optimum counting time for the speed, the net SNM source count will decrease linearly as speed increases simply because the SNM is present for proportionately less time. Slower speed, of course, allows longer counting time and better sensitivity. A monitor designed to operate best at a certain speed will operate with less than optimum sensitivity when vehicles pass through at speeds both below and above the design speed.

Speed is a factor in hand-held monitoring as well. A slow-moving instrument has a better chance than a fastmoving one to detect any SNM that may be present. On the other hand, monitoring must be fast enough to complete a thorough search within a reasonable monitoring delay.

\section{EXAMPLES OF VEHICLE SNM MONITOR DETECTION SENSITIVITY}

Vehicle monitors come in a variety of types as do pedestrian monitors. There are three basic types of vehicle monitor being used today, hand-held, vehicle portal, and the vehicle monitoring station. Unlike the performance of pedestrian monitors, the performance of each type of vebicle monitor is, to some extent, affected by its particular mode of monitoring. Hence, it is not possible to give a universal scale of performance for vehicle monitors as has been done for pedestrian portal monitors. Instead, we can only attempt to make a worstcase performance estimate for each basic type of vehicle monitor as it monitors a sp cific vehicle. Keeping with our practice of quoting worst-case performance, we will estimate performance for one of the vehicles with lowest detection probability in Table $I$, the small van.

Small van in this case refers to a I-ton-class recreational vehicle carrying a certain amount of cargo, which is small in comparison with a bread truck or a moving van. The other worst-case factors in the estimate are that the SNM is low-burnup plutonium or HEU with maximum self-attenuation of its emitted radiation and that the background intensity is relatively high, $20 \mu R / h$. Standard monitoring procedures are used, and for the hand-held monitor a spread in performance for routinely trained personnel is estimated. The minimum detectable SNM masses in Table II range from the monitoring station value similar to a pedestrian monitor's to a much larger value for the vehicle portal monitor. This reflects the vehicle portal monitor's intended purpose as a rapid means for monitoring where only large amounts of material need to be detected. Remember that these are worst-case estimates and that performance with low background intensity, small or transparent vehicles, or routine forms of SNM improves the performance of any monitor.

Monitoring effectiveness for routine conditions or for more radioactive forms of SNM such as ${ }^{233} \mathrm{U},{ }^{238} \mathrm{Pu}$, or reactor-grade plutonium containing $12 \%$ or more ${ }^{240} \mathrm{Pu}$ is, of course, better; and the detectable masses of these materials are smaller than those in Table II under otherwise identical circumstances. On the other hand, additional shielding placed around the SNM diminishes its emitted radiation intensity and increases the detectable masses of any type of SNM. The effect is most noticeable for HEU, which depends on gamma rays alone for detection. Plutonium shielding is less effective because neutrons are more difficult to shield and give a persistent signal. An example of the effects of neutron and gamma-ray shielding on plutonium radiation is Fig. 7 of Ref. 2. Shielding is discussed further in Part II of this guide, where the relative merits of gamma-ray and neutron detection are discussed. 


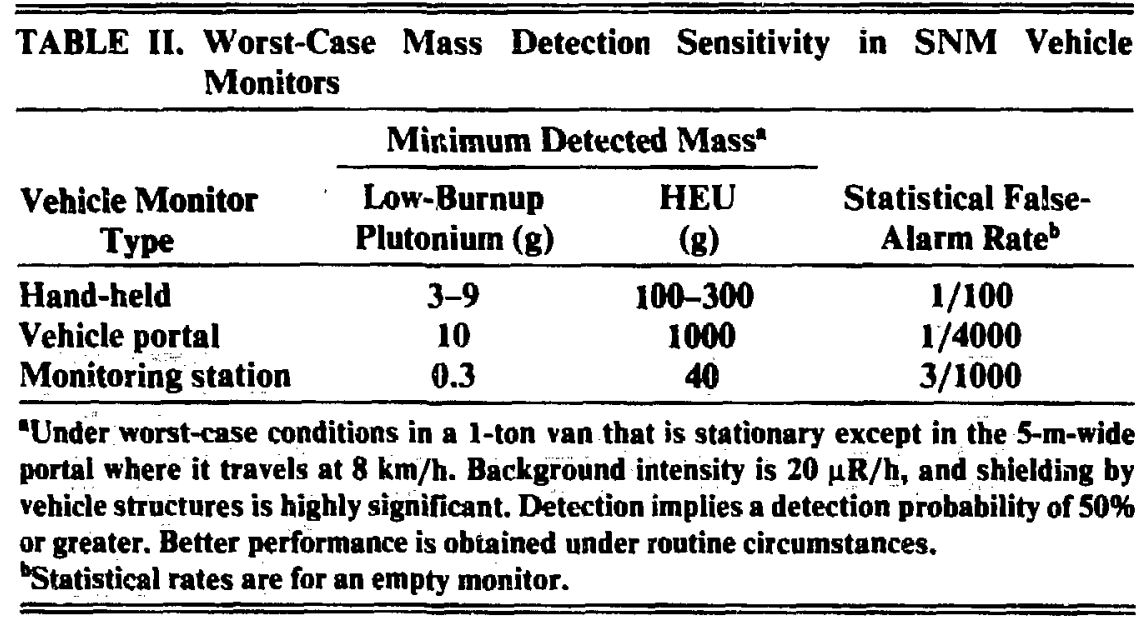

\section{APPLYING VEHICLE SNM MONITORING TECHNOLOGY}

The first step in any monitoring application is the planning. The most important step in planning is to select an appropriate location for the monitor. The location must offer convenience and fit well into perimeter security plans. In addition, it should offer a reasonable radiation environment and as good a climate as possible for year-round operation. The best radiation environment is the natural one of the surrounding landscape. Any facility contribution should be as low as possible. Locations near hot cells, radioactive process streams, or radioactive material shipping areas are poor choices. Such highly varying background locations decrease sensitivity and introduce nuisance alarms.

Besides the radioactive environment, weather protection also is important. It is most important for handheld monitoring where an individual must move in and around each vehicle to search. Enclosing the monitoring area in a shed provides ideal protection, but a canopy may suffice. Automatic monitors require less protection, but investigation of alarms requires hand searching as does a contraband search of incoming vehicles. Other considerations for applying a vehicle monitor are explained below by monitor type.

\section{A. Hand-Held Monitors}

1. Applications. Hand-held SNM monitoring is the easiest method to apply because no installation is required. If not already selected, a monitoring location should be chosen that is free from unnecessary interference from facility-produced radiation. Once the monitors have been purchased, the operators can be trained to use them (Fig. 7) with the help of Ref. 3, the hand-held-monitor user's manual (available from the author $r^{*}$. Instruments and small radioactive sources, I $\mu \mathrm{Ci}$ of ${ }^{133} \mathrm{Ba}$ for example, should be available during training to allow the trainees to detect a radiation intensity similar to a small quantity of SNM. Supervisors also need training so that they can effectively enforce good monitoring practice. Maintenance for the monitors must be provided locally; hand-held monitors should be tested by operators or maintenance personnel on a daily basis to make sure that they detect radicactive material ( $1 \mu \mathrm{Ci}$ of ${ }^{133} \mathrm{Ba}$, for example). If they do not, the monitors should be repaired.

2. Testing. Besides the daily source tests described above, quarterly tests with a $10 \mathrm{~g}$ HEU test sphere (available to DOE contractors from the author) adequately verify SNM detection sensitivity. The test procedure must detect the test sphere at a $15-\mathrm{cm}$ (6-in.) distance when the hand-held instrument moves past at $0.5 \mathrm{~m} / \mathrm{s}$. A desired detection probability of $50 \%$ can be verified using Fig. 33 of Ref. 1. For example, 5 detections in 5 trials, or 9 in 10 , or 8 in 12 would suffice to verify $50 \%$ detection with $95 \%$ confidence. ${ }^{* *}$ These repeated trials are easy to do with hand-held monitors.

\section{B. Vehicle Portal Monitors}

1. Applications. Vehicle portals are used only where relatively large quantities of SNM or highly radioactive forms of SNM must be detected. For example, fabri-

"Paul E. Fehlau, Los Alamos National Laboratory, MS J562, Los Alamos, NM 87545, (505) 667-5372 or FTS 843-5372.

*A $50 \%$ detection probability describes the monitor, whereas the $95 \%$ confidence value describes the precision of the test procedure that measured it. 


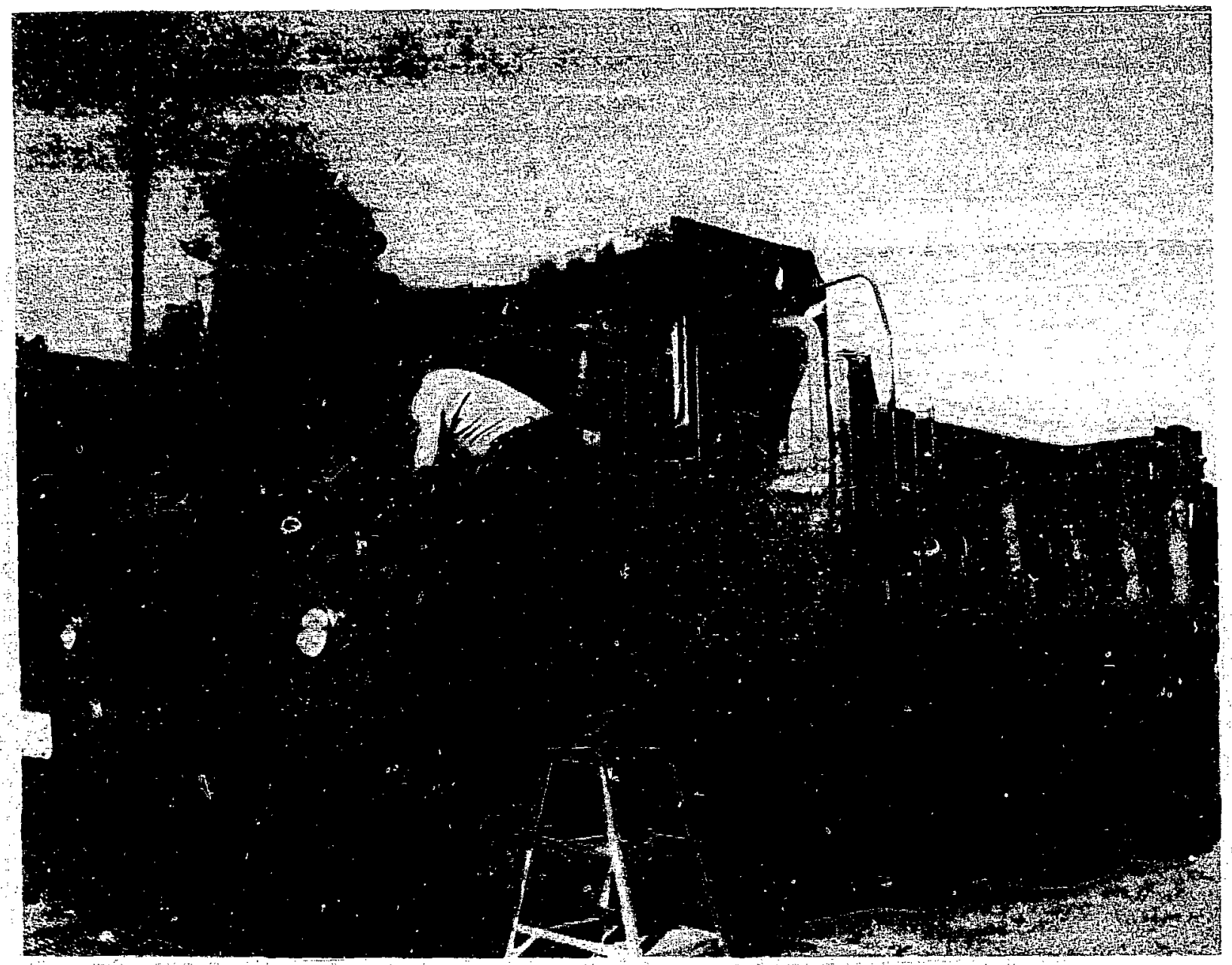

Fig. 7. Operators of hand-held monitors can thoroughly search vehicles if they are well trained in the technique and are provided the means to do so.

cated items containing a $10-\mathrm{g}$ (or larger) quantity of lowburnup plutonium, kilogram quantities of HEU, or such irradiated material as spent fuel must be detected. Other highly radioactive forms of $S N M$ are ${ }^{238} \mathrm{Pu},{ }^{233} \mathrm{U}$, and high-burnup plutonium.

Vehicle portals are best used at a location where vehicles are moving slowly and background radiation intensity is relatively low and constant. Vehicles slowing down as they approach a gate or just beginning to move after a gate has opened move about $8 \mathrm{~km} / \mathrm{h}$, a good speed for monitoring. Speed bumps are effective but are often not allowed for safety or cons fort reasons. Even at slow speeds, vehicles can damage a monitor if they strike it; therefore, one essential part of installing a vehicle portal is to provide protection in the form of crash barriers, such as well-anchored concrete-filled pipe, around the detector and electronics cabinets.

Interconnections between detector and electronics cabinets and between the electronics cabinet and a guard station should be contained in buried conduit to dis- courage tampering. Traffic sensor loops can communicate with a controller through direct burial cable. In this case, adequate tamper protection is usually provided by sounding a chime or buzzer and by flashing a lamp whenever a vehicle is sensed to confirm that monitoring is taking place.

Two methods of installing detector and electronics cabinets have been used. One simply uses insulated wire rope between eyebolts in the cabinets and eyebolts attached to anchors or posts (Fig. 8). Support for each cabinet is provided by a concrete pad or paved surface. Conduit comes out of the ground nearby and enters the cabinet floor or side. Another method supports the detector cabinets against channel or I-beams that are placed in concrete-filled holes. Similarly, electronics cabinets can be supported on a concrete pad with embedded anchor bolts that pass through mating holes in the cabinet floor. Where active cooli.," for cabınets is by air conditioner or thermoelectric cooler, cabinet penetrations should be sealed against moisture. Also, 


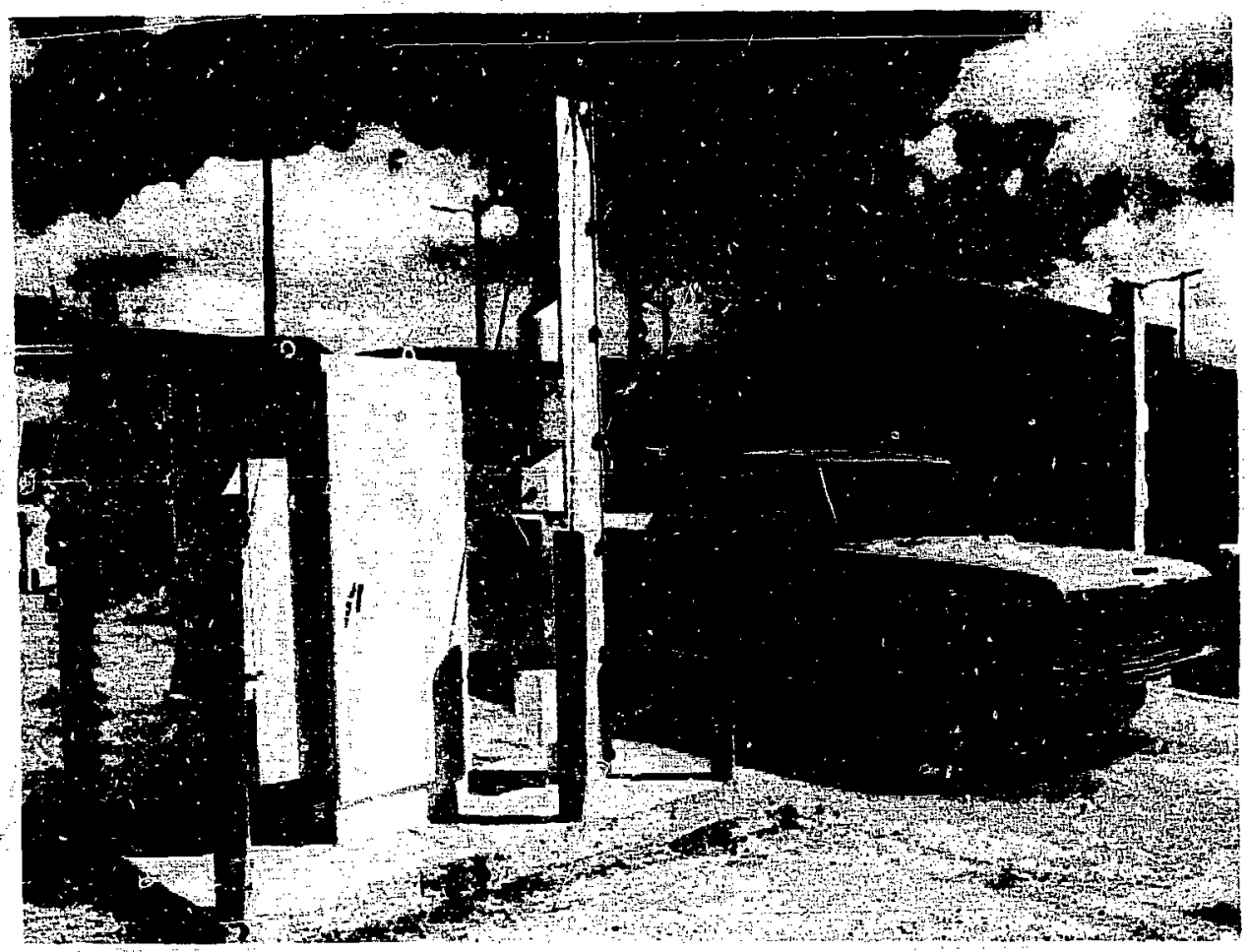

Fig. 8. The vehicle portal monitor detectors are supported by guy wires attached to concretefilled posts that protect the detector cabinets from vehicles.

cabinet orientation should position the cooling device on the shady side to minimize the heat input through the air conditioner, which is usually the least-insulated part of the cabinet.

Vehicle detectors may be either current loops in the roadway or buried discrete sensors. In each case, pavement cuts are repaved or filled with a crack-sealing compound once the sensing element is in place. Positions for the vehicle sensors must be chosen to provide monitoring during the entire time a vehicle is between the detectors.

Two methods have been used to analyze vehicle portal signals. One sums signals from both sides of the roadway to obtain the highest sensitivity at the roadway center. The other has independent monitors on both sides of the roadway, providing high sensitivity near each detector cabinet but providing about $40 \%$ lower sensitivity at the midpoint of the roadway. The first method would certainly be used for single-lane traffic where the detectors are spaced no more than 5 or $6 \mathrm{~m}$ apart. The second would be used for two-lane traffic with at least a 7-m detector spacing. In this case there is no need to achieve maximum sensitivity at the roadway center, but both sides of the roadway must be monitored to reduce the effectiveness of shielding by vehicle structure or contents.
2. Testing. Once the vehicle portal monitor is operational, it must be properly calibrated, tested, and maintained. Daily testing with a radioactive source will verify that the system is intact and operating. Monitors having a test mode started by depressing the alarm reset button when the monitor is unoccupied can be tested by a second person walking down the center line carrying an $8-\mu \mathrm{Ci}{ }^{137} \mathrm{Cs}$ source that is used to calibrate the monitor. This suffices for 5- to 6-m spacing under worstcase conditions. A somewhat stronger source would be necessary for more widely spaced portais unless background is lower than $20 \mu \mathrm{R} / \mathrm{h}$. Another source that somewhat resembles thi plutonium gamma-radiation spectrum is ${ }^{133} \mathrm{Ba}$; a $6-\mu \mathrm{Ci}$ size carried by a person through the portal center should be adequate. If sources are carried in vehicles, they may have to be larger than mentioned above at $20-\mu \mathrm{R} / \mathrm{h}$ background. The size will depend on the vehicle and position of the source within the vehicle.

The vehicle sensors must also be tested, but no separate test is required if the monitor's normal operation notifies the guard audibly as well as visually each time that a vehicle is present.

Periodic recalibration should take place at least each calendar quarter. This can include testing with SNM if suitable test sources are available. Standard test sources 
are available to DOE contractors from the DOE Rocky Flats plant * $10-\mathrm{g}$ metallic ${ }^{239} \mathrm{Pu}$ source having $6 \%$ ${ }^{240} \mathrm{Pu}$ can be fabricated for $\$ 1200$. The source is shielded with cadmium $0.040 \mathrm{~cm}$ thick and is triply encapsulated in aluminum.

\section{Vehicle Monitoring Stations}

1. Applications. Veỉicle monitoring stations are used where the highest sensitivity is required. High sensitivity is achieved by positioning detectors as close to vehicles as possible, analyzing data from small groups of detectors to maximize the importance of a diversion signal, and counting for the longest practical period of time.

Vehicle monitoring stations require more construction than do other vehicle monitors. A framework is needed to support the overhead detectors, and irenches are needed for the below-vehicle detectors. At Los Alamos a monitor having detectors spread over a 3-by $6-\mathrm{m}(10-$ by $20-\mathrm{ft})$ area and having a $4.3-\mathrm{m}$ (14-ft) vertical clearance suffices for most vehicles (Fig. 9). Longer vehicles are monitored in two stages.

The Los Alamos vehicle monitoring stations have six concrete detector trenches for the below-vehicle detectors. The transverse trenches are $30 \mathrm{~cm}(1 \mathrm{ft})$ wide and are spaced on 1.2-m (4-ft) ceitters along the path of a vehicle. Each trench is drained to a sump (a drain to daylight would be better) to keep the detector area dry. Trenches are covered with aluminum diamond plate to support vehicles without severely attenuating radiation. Detector cabinets lie on the trench floor and have attached conduit for wires going to and from the electronics cabinet.

Overhead detector support is provided by shed or canopy rafters above a roadway. At Los Alamos a canopy $5.5 \mathrm{~m}(18 \mathrm{ft})$ tall supports the overhead detectors; the canopy, which also supports area lighting, provides weather protection during incoming-vehicle contraband inspection. Detector cabinets are suspended below the canopy by hangers that position the detectors

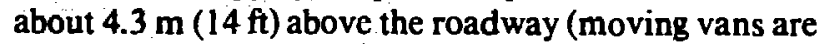
about $4.2 \mathrm{~m}$ [13 ft, 9 in.] tall).

Occupancy can be detected with a roadway vehicle detector loop or other device. At Los Alamos a single traffic loop at the center of the monitor detects and starts monitoring for both incoming and outgoing traffic. Monitoring incoming traffic prevents introducing contaminated laundry or other radioactive material that will later be difficult to remove from the area.

"Contact R. Koelmel for information at (303) 966-7421 or FTS 320-7421.

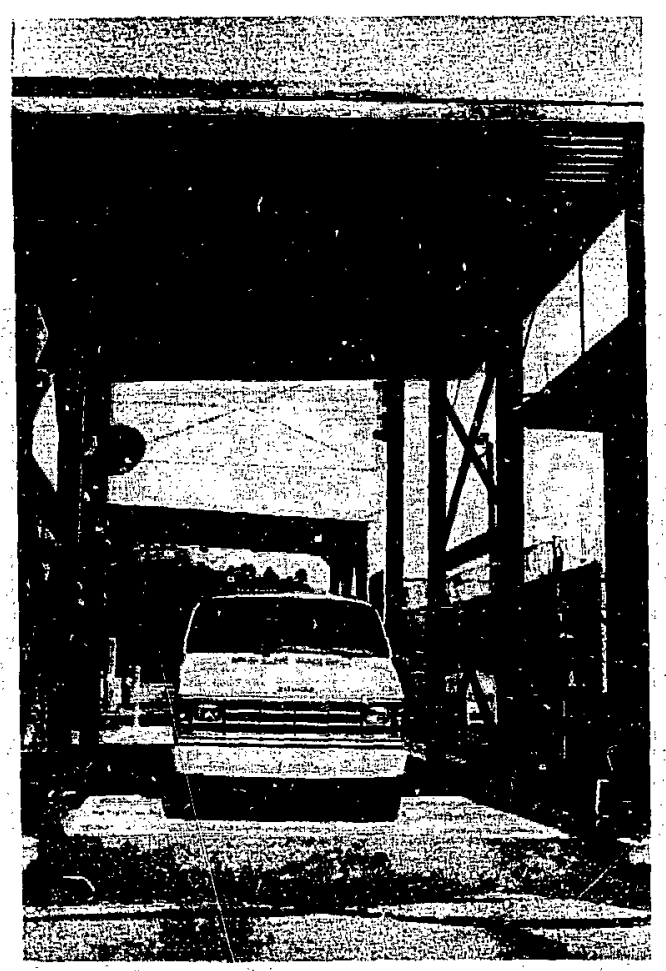

Fig. 9. The commercial version of the Los Alamos vehicle monitoring station also has both underground detectors in trenches below the vehicle and overhead detectors that are supported from a canopy.

Monitoring-station electronics are housed in a separate cabinet located near the inspection station (Fig. 19). Communication between sectrity inspectors and the monitor is provided by two modules, one located inside the hardened area of the station and one located outdoors near the vehicle. The information to be communicated is monitor status-unoccupied, occupied and monitoring, monitoring result, out of service-and alarm reset commands. Different colored lamps and sonic tones carry most of the information, but out-of-service status generates a verbal instruction to monitor the vehicle with a hand-held monitor.

Calibration and maintenance can be more troublesome for vehicle monitoring stations than for other types of monitor because the individual detectors are not readily accessible. The underground detectors are inconvenient to work on; removing the diamond-plate trench covers and opening the detector cabinets reveal the detectors themselves well below ground level, an awkward place to work. The overhead detector cabinets are a little easier to work on for those with no fear of height. A portable pneumatic lift with widespread stabilizing legs can provide a relatively inexpensive, safe work platform at the required height. In both cases, the detectors are unlikely to be near the electronics cabinet; hence, two individuals who communicate well with one 


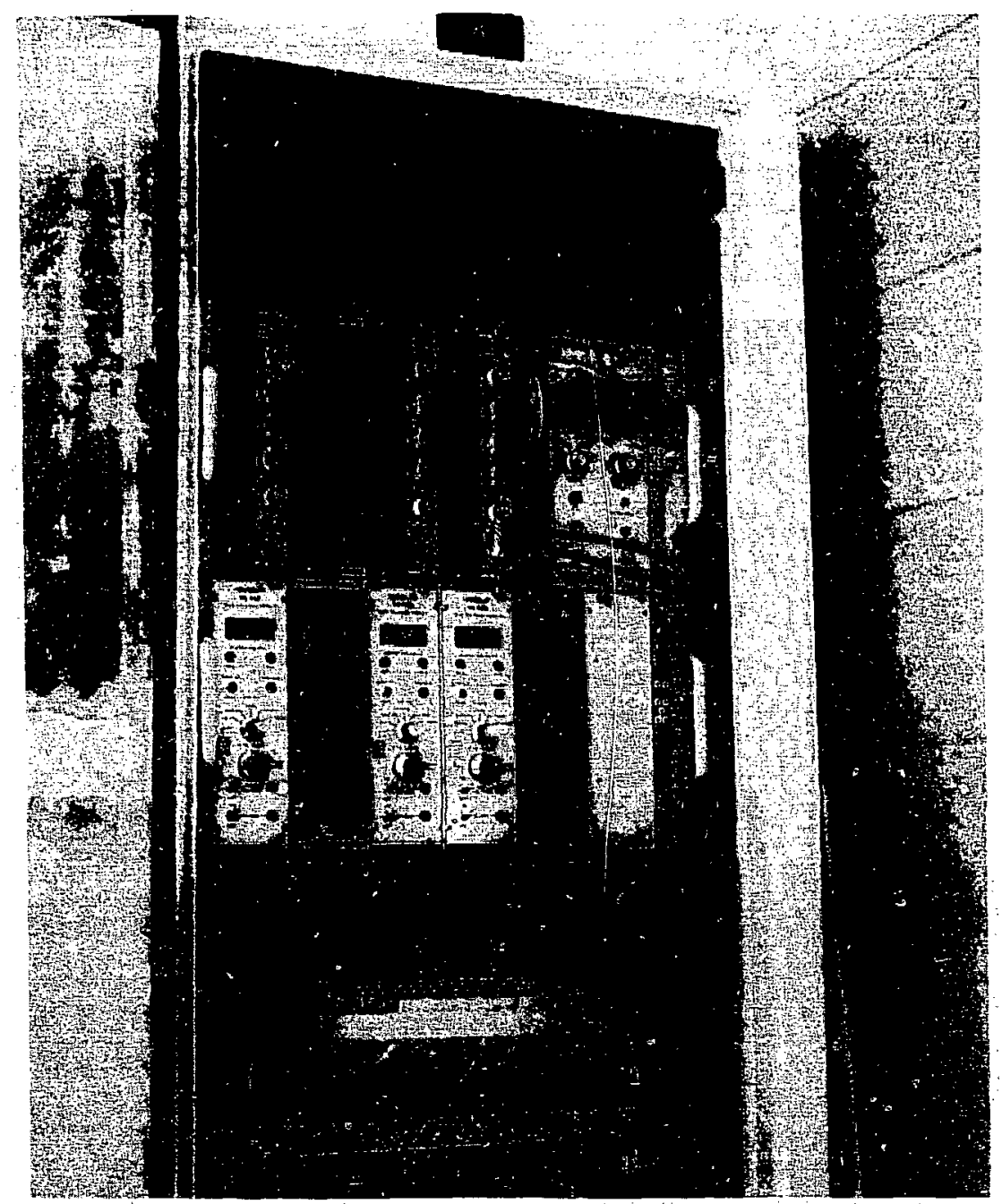

Fig. 10. The vehicle monitoring station electronics is housed in a cabinet that also contains a teletype for changing operating parameters and listing output.

another, perhaps by intercom, are needed to calibrate or repair the monitor's detectors.

2. Testing. Daily testing also is more complex for vehicle monitoring stations than for other monitors. Testing individual overhead detectors requires that the source be attached to a long wand to reach the detectors, and a relatively long time is needed to test all of the detectors. If all detectors cannot be tested each day, each should be tested within a week. The size of the test source for monitoring stations can be as small as $1 \mu \mathrm{Ci}$ of ${ }^{133} \mathrm{Ba}$ if testing is done in an unoccupied monitor. A test mode in the Los Alamos station is entered by depressing the alarm reset button when the monitor is unoccupied. The source can then be held within 2 to $3 \mathrm{ft}$ of each detector, which should then alarm. If it does not, remove the source, obtain a new background, and try again. Any lack of response should be investigated and repaired.
Standard plutonium test sources for quarterly tests can be fabricated by the DOE Rocky Flats plant for about $\$ 1200$ * A $1-\mathrm{g}$ metallic ${ }^{239} \mathrm{Pu}$ source having $6 \%$ ${ }^{240} \mathrm{PL}$ is appropriate for testing.

\section{COSTS OF SNM VEHICLE MONITORS}

Hand-held SNM monitors for monitoring vehicles are the least expensive to buy; today their price begins at about $\$ 1650$ and ranges up to perhaps double that for off-the-shelf units. The purchase price includes the monitor, battery charger, perhaps an earphone, and an operation or service manual.

*Contact R. Koelmel for information at (303) 966-7421 or FTS 320-7421. 
Vehicle portal monitors are an inexpensive type of automatic monitor. In recent years they have ranged from $\$ 20,000$ to $\$ 45,000$ depending on the complexity of the monitor's detectors, electronics, and climate control system. Installation can cost $\$ 7,000$ or more to provide power, conduit for interconnections, concrete pads for detector support, barriers to protect the cabinets from damage, and vehicle sensors in the roadway.

Vehicle monitoring stations cost about $\$ 70,000$ for the detectors, electronics, and cabinets. Installation requires concrete work to provide well-drained trenches (preferably above grade) and materials and structural work for the canopy. A construction cost of about $\$ 75,000$ is required if an existing canopy or shed is not available.

\section{OPERATING VEHICLE MONITORS}

Hand-held vehicle monitors require operator training and supervision. Training can make use of the handheld-monitor operator's manual, ${ }^{3}$ which is available from the author. In addition to the manual, equipment and sources should be available to permit students to have hands-on experience in locating radioactive material with hand-held monitors. Hand-held instruments, small sources such as $1 \mu \mathrm{Ci}$ of ${ }^{133} \mathrm{Ba}$, and vehicles can be provided, and some of the students can hide sources in the vehicles for others to find. Such practice is essential because it gives the students some idea of how thorough a search must be to detect threshold quantities of SNM, an experience that will rarely be found on the job.

Automatic monitors require less operator training. However, an automatic monitor alarm may require a manual search to find the cause; in which case, the training described in the preceding paragraph is essential. The automatic monitor is just that and should carry out all of its functions without operator intervention. Usually, lamps are used to indicate that the monitor is operating and measuring background, is occupied and monitoring, or is alarming. The operator must understand what these signals mean. Audible sounders also indicate alarms, and a chime can be used to indicate occupancy and monitoring. An alarm can be automatically or manualiy silenced and should call for an investigation of the cause by the operator. If the vehicle's occupants cannot identify the cause, the monitor's operator can manually search for the cause. In some cases, the station operating protocol calls for the area SNM custodian or a health monitor to assist in resolving an alarm. If the cause of the alarm is not quickly discovered, the vehicle can be moved back into the protected area for a more thorough search. If nothing is discovered, the vehicle can be remonitored in the automatic monitor.

Resolving an alarm may require some understanding of materials found in commerce that are in fact radioactive. Usually, after a monitor has been operating for a while, certain items become well-known causes of alarms. When that happens, they should be excluded from the area, if possible. Such items that have been found are the following: truckload quantities of thermal insulating material, quantities of aluminum alloys containing thorium, camera lenses containing thorium, butane gas cylinders containing radon, soil from areas where uranium and potassium are common, soiled anticontamination clothing, smoke detectors containing ${ }^{241} \mathrm{Am}$, shipments of drainage tile, and shipment quantities of gasoline lantern mantles containing thorium.

\section{CALIBRATION AND MAINTENANCE}

Calibration is called for when maintenance service is rezuired and when a detector fails a daily operational test. Otherwise, calibration should be performed routinely on a quarterly (3-month) basis. Calibration first verifies or adjusts each detector to give the same pulse height response to a particular gamma ray. An ${ }^{8}-\mu \mathrm{Ci}{ }^{137} \mathrm{Cs}$ source is ideal for this because it is a longlived isotope that emits $662-\mathrm{keV}$ photons, which in this size source produce pulses that are easily seen on an oscilloscope attached to the amplifier analog output. Once each detector gives an identical response, $3.3 \mathrm{~V}$ for example, the single-channel analyzer (SCA) is adjusted by observing the same signal on the uscilloscope, now triggered by the SCA pulse. A delay amplifier between the monitor's amplifier and the oscilloscope may be necessary to observe the complete pulse on the oscilloscope trace.

The SCA adjustment selects a gamma-ray region that typifies SNM, generally about 60 to $450 \mathrm{keV}$. Where HEU is the only material being monitored, the SCA window can be narrowed to 60 to $220 \mathrm{keV}$. And in each case, if a variance analyzer* is available, the SCA's lower sill can be lowered to just above the noise to obtain highest detector efficiency. Table III gives an example of the detector pulse heights observed during calibration and SCA adjustment of the plastic scintillation detectors used in almost all automatic vehicle monitors. Notice that the plastic scintillators have a nonlinear response to

\footnotetext{
-The variance analyzer and its use for calibrations are described in Ref. 1, pp. 35 and 37, respectively.
}

-Paul E. Fehlau, Los Alamos National Laboratory, MS J562, Los Alamos, NM 87545, (505) 667-5372 or FTS 843-5372. 


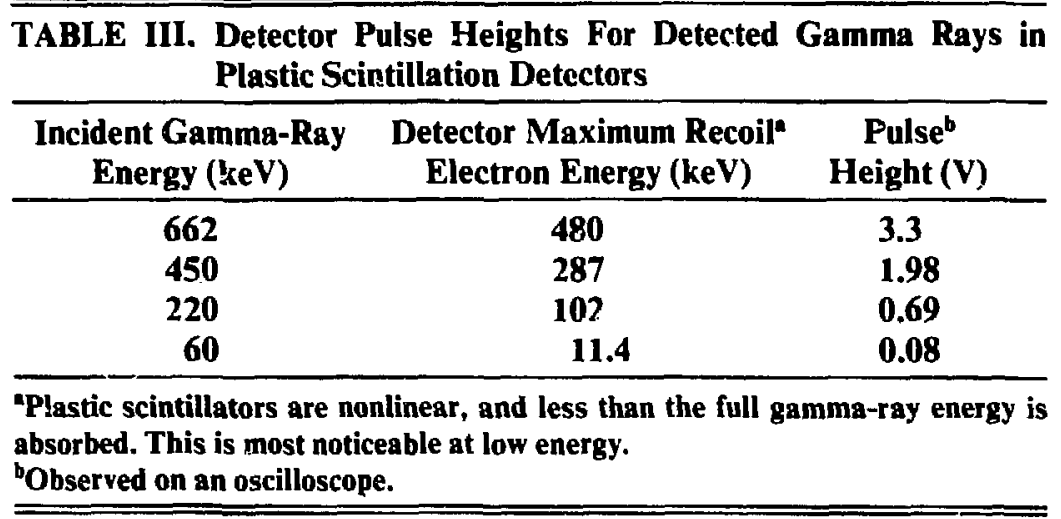

gamma rays, and not much energy is transferred to recoil electrons in the detector by low-energy gamma rays. Once the SCA is set, detector calibration is complete.

The other details of calibration such as photomultiplier operating voltage and detection logic parameters may be unique to each monitor. Generally, operating voltages need be no higher than $1000 \mathrm{~V}$ when adequate amplifier gain is available (about 1250 maximum gain for plastic scintillators).

Each monitor should have a calibration manual that outlines the calibration steps. Unfortunately, calibra. tion manuals are easily lost or are inappropriate for SNM monitoring. Los Alamos has written and provided calibration manuals for many SNM monitors used by
DOE contractors; the author will be happy to provide copies of them.*

Maintenance of monitors is requested less often when they are kept properly calibrated. If frequent component failures occur, the cause should be corrected sitil 2 longer-lived replacement. For example, indicator lamp lifetimes may be extended with series resistance that reduces operating current. Most parts of vehicle monitors are long-lived and require little attention.

*Paul E. Fehlau, Los Alamos National Laboratory, MS J562, Los Alamos, NM 87545, (505) 667-5372 or FTS 843-5372. 


\section{PART 2}

\section{TECHNICAL ASPECTS OF VEHICLE SNM MONITORING}

The technical basis for monitoring both pedestrians and vehicles is well covered in Refs. 1 and 2. These publications discuss the development history of $\mathrm{FVM}$ monitoring and describe the radiation sinitieci by SNM. Background sources of radiation are described as well, and the influence of stisiling materials on radiation intensity is discussed. Detectors and associated signalconditioning circuits and analysis methods are destribed and compared. What remains to be discussed are the technical aspects of vehicle monitoring that have been investigated in recent years. These topics are detecting shielded SNM in vehicles, recently developed analysis methods to improve the performance of vehicle monitors, and development of lightweight, neutronsensitive hand-held monitors. Additional information about commercial monitors that have become available in the last few years may be found in the catalog of SNM vehicle monitors in Part 3.

\section{DETECTING SHIELDED SNM IN VEHICLES}

Shielding materials reduce the sensitivity of any SNM monitor by absorbing part of the radiation emitted by SNM. Gamma rays are shielded best by heavy materials such as lead, whereas neutrons are shielded best by lighter substances containing moderators and absorbers, boron-loaded polyethylene for example. Lead shields are seldom thicker than $5 \mathrm{~cm}$, but neutron shields are not highly effective unless they are very thick, $15 \mathrm{~cm}$ or more. The solution to maintaining the sensitivity of a monitor when shielding is present is to make the monitor as effective as possible and, where plutonium is involved, to make the detectors both gamma ray and neutron sensitive.

The question of effectiveness in monitoring is related to the amount of radiation that is absorbed and counted in the monitor. For the most effective form of monitor, the radiation detectors are placed as near as possible to a vehicle, and monitoring takes place while the vehicle is stationary. Such a monitor is the Los Alamos vehicle monitoring station briefly described in Part 1 . The monitoring station places four or more independent groups of detectors around the vehicle, each group having its own signal conditioning and detection circuits. The group concept concentrates signals from particular areas of the vehicle into a few local detectors. Each group has only a few detectors and relatively low background; hence, the concentrated signal is much larger relative to background than it would be without grouping. As a result, detection sensitivity is improved, and the monitor becomes very effective at detecting bare and shielded SNM.

Neutron sensitivity in a monitor's radiation detectors improves its nestersance in detecting shielded plutonium or the nonmetallic forms of HEU that emit neutrons, such as $\mathrm{UF}_{6}$ or $\mathrm{UO}_{2} \mathrm{~F}_{2}$. Two types of neutronsensitive detector can be used, plastic scintillation detectors that are neutron and gamma ray sensitive or ${ }^{3} \mathrm{He}$ and $\mathrm{BF}_{3}$ proportional counters that detect neutrons alone in this application. The major difference between these two types of detector is that plastic scintillators are useful for general-purpose SNM monitoring, detecting all types of SNM, whereas proportional counters are specialized for detecting neutron-emitting materials.

\section{A. Vehicle Monitoring Stations}

The basic vehicle monitoring station developed at Los Alamos was illustrated in Figs. 5 and 6. The station has four detector groups, three below the vehicle and one above it. Each detector group has four large plastic scintillation detectors housed in pairs inside weathertight cabinets below the roadway or singly in smaller cabinets overhead (Fig 11). The plastic scintillators respond to all radiation from SNM; their ability to detect neutrons and other relatively hard radiation that can be transmitted through shielding material is their strong point.

1. Detectors. Plastic scintillation detectors are a natural choice for vehicle monitoring because SNM inside a vehicle is always shielded to some extent. The long narrow shape of the detectors (Fig. 11) is well suited to cover the area that must be monitored. For example, two underground detectors can easily monitor the width of a vehicle. The narrow detector width also is beneficial, allowing the scintillators to be housed in $30-\mathrm{cm}$-wide trenches that are easily covered with aluminum diamond plate, which absorbs little radiation.

The group of four overhead detectors views the vehicle through the roof where there usually is littie radiation attenuation; hence, the entire vehicle can be monitored by a single group. The overhead detectors rule out simple shadow shielding of SNM by massive items being transported in the vehicle. In cases where significant attenuation in the upward direction is likely, additional detectors can be added at the sides of the monitor. Figure 12 illustrates a system to monitor long vehicles from above, below, and both sides.

2. Monitoring-Station Electronies. Signal analysis is simultaneous for all detector groups in a monitoring station, each of which must reach a background decision 


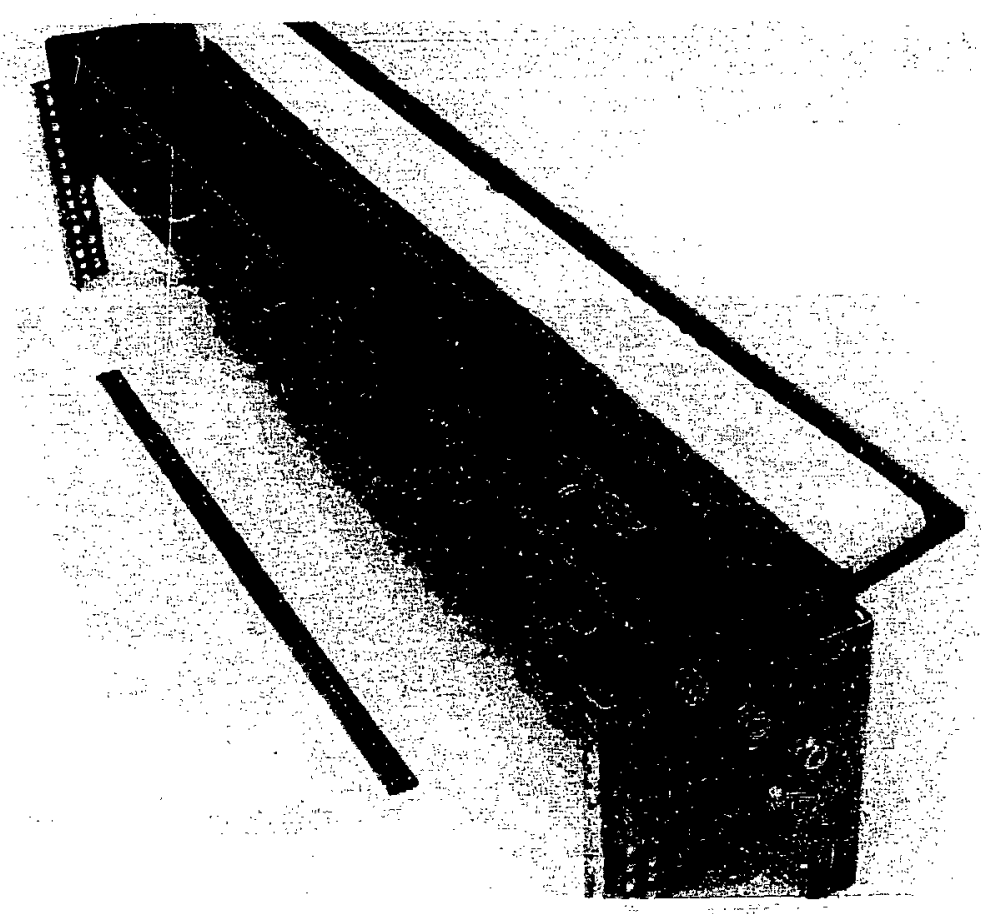

Fig. 11. Monitoring station detectors are plastic scintillators 91 by 7.6 by $3.8 \mathrm{~cm}$ ( 36 by 3 by 1.5 in.) housed with a preamplifier in weathertight cabinets similar to this one.
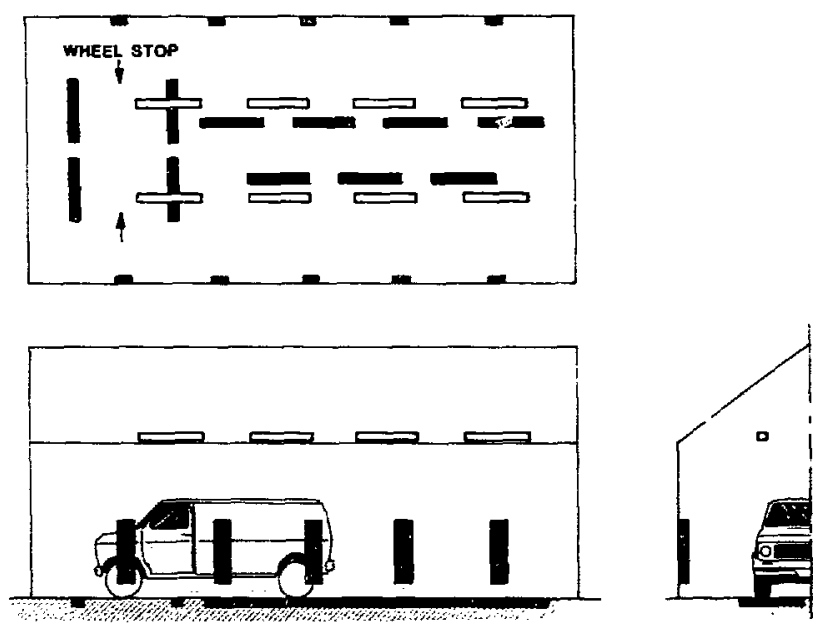

Fig. 12. This expanded monitoring station surrounds tractorpulled wagons (not shown here) with detectors that view radiation emitted in almost any direction.

to rule out an alarm. The extended measurement time in monitoring stations-up to about a minute for monitoring and 2 min for background-makes them susceptible to alarms caused by varying background intensity. New analysis methods to minimize that influence keep the background measurement as current as possible with a moving average ${ }^{6}$ and shorten the monitoring time without loss of sensitivity or increased false-alarm rate with sequential testing. The background is partially updated during any unoccupied period of $4 \mathrm{~s}$ or more, and sequential testing ${ }^{6}$ makes monitoring decisions at the earliest possible moment, requiring on the average only about one-fifth the time that would otherwise be needed. Sequential testing is described in greater detail in Sec. I.B.

Figure 13 illustrates the control unit and communication modules for the monitoring station. The basic controller operates four detector groups, and expansion to as many as eight groups can be attained by adding another circuit board to the module. In addition to its monitoring function, the controller has an operating mode that allows it to print diagnostic information during operation. Diagnosțic information includes statistical analysis of signals from each detector group and listings of the following: monitor occupancies with information on each decision, any power interruptions or program watchdog restart commands, and any background determinations that exceed high and low thresholds. The controller, located in a locked electronics cabinet, communicates with the operator by means of a remote module having indicator lamps, audible sounders, and a speaker for voice commands. Vocal announcement that hand-held monitoring is required is generate. service from high or low background. 


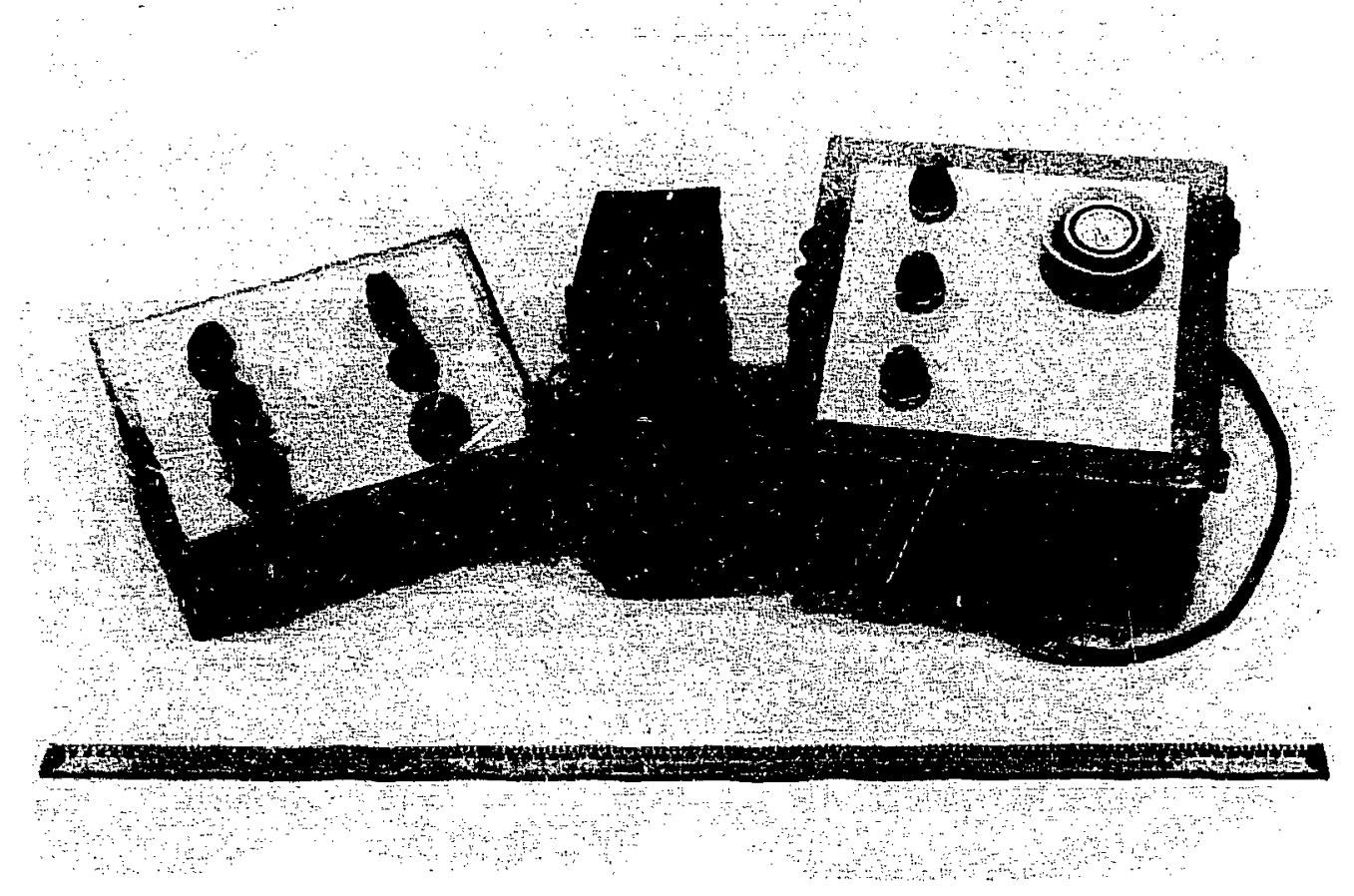

Fig. 13. The vehicle monitor controller at the center makes measurements and monitoring background or alarm decisions. Communication with security inspectors is by two separate information modules.

Operating parameters for the controller are changed by teletype input. The information is stored in an electricaliy alterable memory, which preserves the information without requiring back-up power and which allows the system to restart with the same parameters after any power failure. The parameters set the basic alarm thresholds and background limits as well as other functions that vary the operation of the monitor. For instance, the monitor can operate with manual or automatic alarm reset, with continuous (drive-through) or single-step (parked) monitoring, and with vocal announcements of each occupancy or each $N$ th occupancy. Other monitoring parameters variable by teletype input are a delay to allow vehicles to come to rest before monitoring, the background averaging time, and the monitoring time. The teletype also is used to set the monitor's real-time clock that is used for labe!ing printout. The controller and teletype are located in the locked electronics cabinet, which is protected by tamper-alarm switches.

Automatic monitoring is achieved with standard vehicle-sensing systems used for traffic lights. The vehicle sensors are current loops in the roadway at the middle of the monitor. Traffic in either direction is sensed, and vehicle positioning on the detectors is equalized with symmetrically positioned depressions in the pavement for the vehicle's front wheels. Operating the monitor for both incoming and outgoing traffic prevents introducing radioactive material that later will be difficult to remove. The sensitivity of the vehicle detector can be adjusted high enough to detect bicycles or metal-laden pedestrians and low enough to detect only vehicles.

3. Monitoring-Station Performance. Table II lists the estimated minimum amounts of unshielded SNM that would be detected by a monitoring station when the SNM is carried in a particular vehicle under worst-case circumstances. This section discusses the improved performance of this monitoring station over its predecessor in detecting gamma-ray-shielded plutonium. Although the earlier station (Ref. 2) had $\mathrm{NaI}(\mathrm{Tl})$ detectors with little neutron sensitivity, this one has plastic scintillators with high neutron sensitivity that make it more sensitive to part of the radiation transmitted through gamma-ray shielding. The data plotted in Fig. 14 are the relative detectable masses of low-burnup plutonium in two stations calculated from worst-case source measurements. As stated earlier, these worst-case calculations underestimate routine performance.

The straight line at the left of the figure represents shielded plutonium detected with $\mathrm{NaI}(\mathrm{Tl})$ scintillation detectors. The lower lines are for the overhead and underground plastic scintillation detectors. Although the straight line shows no evidence of neutron detection, the curves illustrate a persistent neutron and promptfission gamma-ray signal. The overhead detectors are 


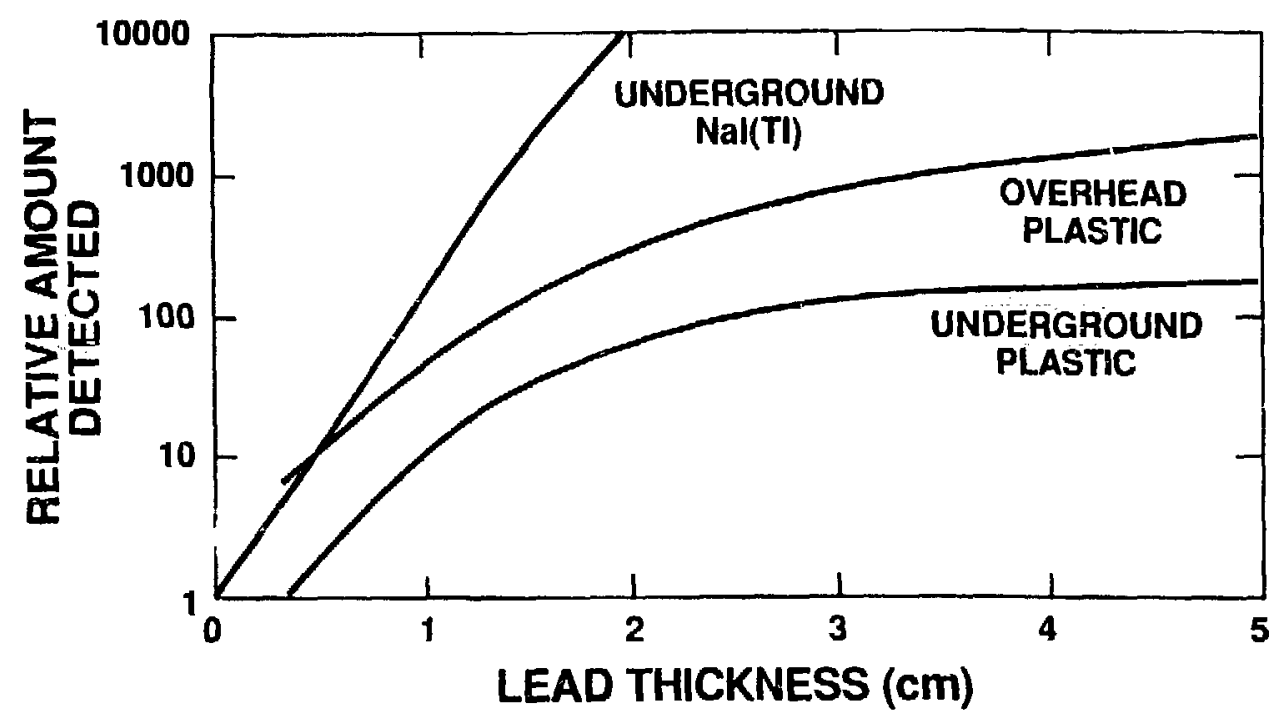

Fig. 14. Relative detectable amounts of shielded plutonium in monitoring stations for underground $\mathrm{NaI}(\mathrm{Tl})$ detectors and for both overhead and underground plastic scintillation detectors. Plastic scintillators benefit from their combined neutron and gamma-ray sensitivity and continue to perform well for thick shielding.

less effective than the underground ones because they are much farther away from the source.

Two aspects of the plastic scintillation detectors help them to perform well at detecting shielded plutonium. First, they are intrinsically efficient at detecting fast neutrons and prompt-fission gamma rays that are transmitted through a shield. Second, their size is large enough to intercept much more of this radiation than would equal-cost $\mathrm{NaI}(\mathrm{Tl})$ detectors in a monitoring station. Intrinsic efficiency for detecting fissionspectrum neutrons in 4-cm-thick plastic scintillators can be as large as 0.5 when a $10-\mathrm{keV}$ recoil-el. sctron bias level is used. $\mathrm{NaI}(\mathrm{Tl})$ detectors, on the other hand, are highly efficient gamma-ray detectors but they are expensive and hence relatively small. Besides not being large enough to intercept many neutrons, they are relatively insensitive to fission-spectrum neutrons. General information on plastic scintillation detectors as used in SNM monitors can be found in Ref. 7.

A final comment on plastic scintillation detectors as neutron detectors is that their performance is limited by the gamma-radiation background. Although the detectors sense both gamma rays and neutrons, neutron background is quite low (perhaps 50 counts per second), whereas the gamma-ray background is appreciable ( 500 counts or more per second). As a result, about three times as much neutron signal is required to cause an alarm at the threshold for detection than if only neutrons were sensed. However, the strong point of the plastic scintillators is their ability to sense both gamma rays and neutrons, which together with their low cost makes them a best buy for general monitoring applications.

\section{B. Neutron Detection in Vehicle Portal Monitors}

1. Monitoring Vehicles in Motion. Vehicle portal monitors are used where the highest gamma-ray detection sensitivity is not required. They have detectors placed beside a roadway to monitor vehicles as they drive through. This is one of the factors that make vehicle portals less sensitive than monitoring stations for detecting SNM. The vehicle portal detectors are also farther away from a vehicle than are some detectors in a monitoring station; hence, they intercept less radiation from SNM carried in a vehicle. Two other factors reduce monitoring signals: the short time that SNM in a moving vehicle is between the detectors and a simultaneous count-rate reduction caused by the vehicle shadowing the portal detectors from environmental radiation as it passes through the monitor. Hence, vehicle portals have modest sensitivity in detecting SNM gamma rays with either $\mathrm{NaI}(\mathrm{Tl})$ or plastic scintillators and in detecting SNM neutrons with plastic scintillators.

The combination of factors reducing sensitivity makes detecting gamma-ray-shielded plutonium under worst-case conditions by a vehicle portal even less likely than by the overhead detectors in Fig. 14. Where higher sensitivity for gamma-ray-shielded plutonium is required, an additional neutron-detecting portal could be used. Adding a neutron portal is more effective than slowing traffic speed, narrowing the gamma-ray portal, or using large-area or additional detectors positioned above and below the vehicle to form a hoop. A neutron portal with detectors that respond to neutrons alone, such as neutron proportional counters (Fig. 15), can be 


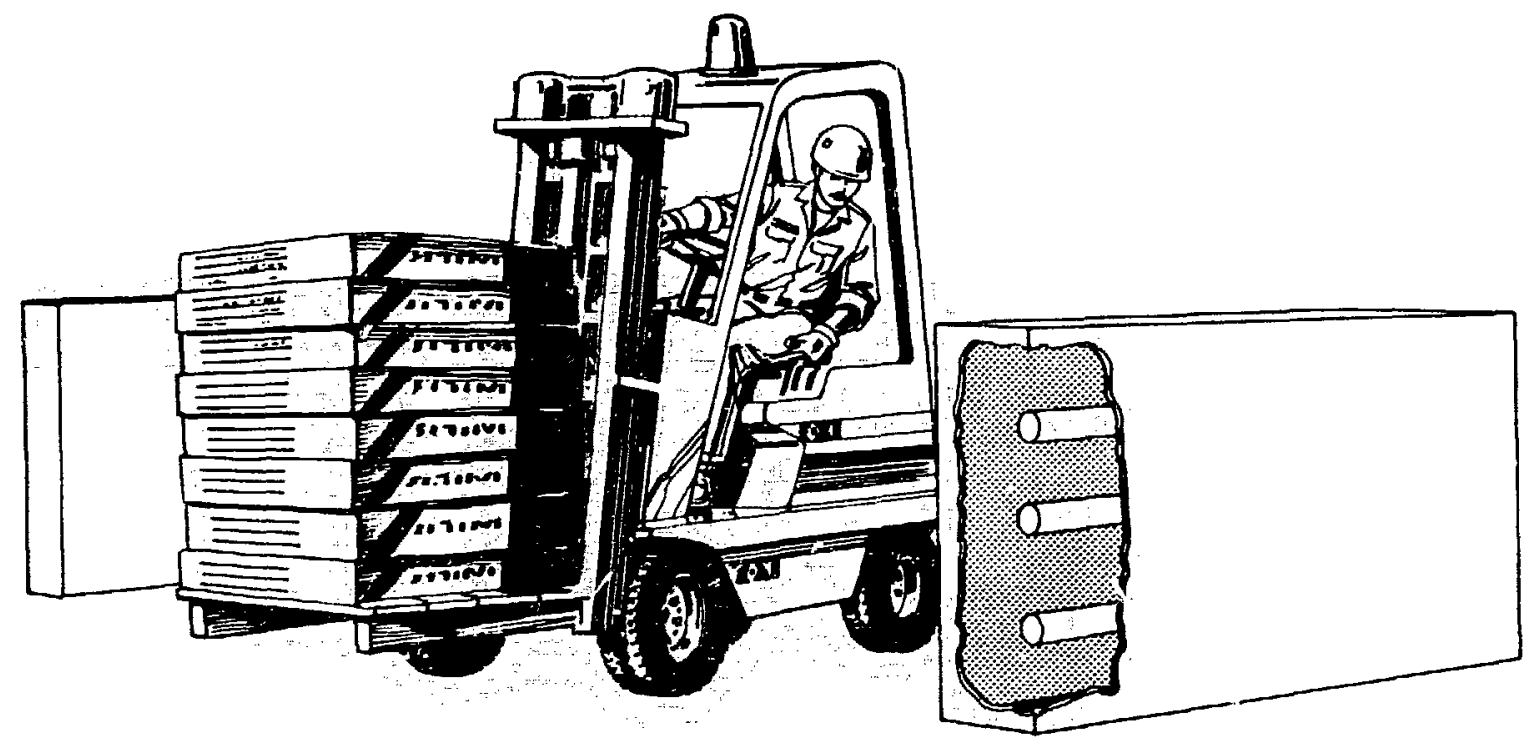

Fig. 15. The concept of neutron portal monitor places detectors that sense only neutrons beside the path of vehicles to be monitored.

used alongside a gamma-ray portal to improve monitoring for gamma-ray-shielded plutonium. The reason that neutron portals are not now used is that their detector cost is usually considerably higher than that for a gamma-ray portal.

2. Neutron Proportional Counters. Neutron proportional counters are a form of neutron detector that has no effective gamma-ray sensitivity and that can be made in large sizes suitable for a vehicle monitor ( 15 to 183 $\mathrm{cm}$ long and 2.5 to $15 \mathrm{~cm}$ in diameter). The courters are gas-filled tubes that detect neutrons but not environmental gamma radiation; hence, they have very low background count rates from only environmental and cosmic-ray-preduced neutrons. Neutron detection takes place in a proportional counter (Fig. 16) when a thermal or epithermal neutron reacts with a converter gas, ${ }^{3} \mathrm{He}$ or $\mathrm{BF}_{3}$, to produce ionizing radiation. An electric field between the counter walls and a center wire collects the charge produced by ionization, giving a current pulse that is amplified and counted in electronic circuits. Although proportional counters are more sensitive to low-energy neutrons, they also detect the more energetic fission-spectrum neutrons from SNM after they are slowed or moderated. Moderation is provides by neutrons colliding with hydrogen in a hydrogeri-rich material, polyethylene for example, surrounding the counters.

There are two different approaches to providing moderation in large-area neutron deiectors. Shown at the left in Fig. 17, proportional counters are embedded in solid polyethylene forming a slab detector. In the slab, moderated neutrons may travel only a centimeter or so before being captured by hydrogen; therefore, the slab is usually deasely packed with proportional counters. Reported intrinsic efficiencies for slab detectors range from

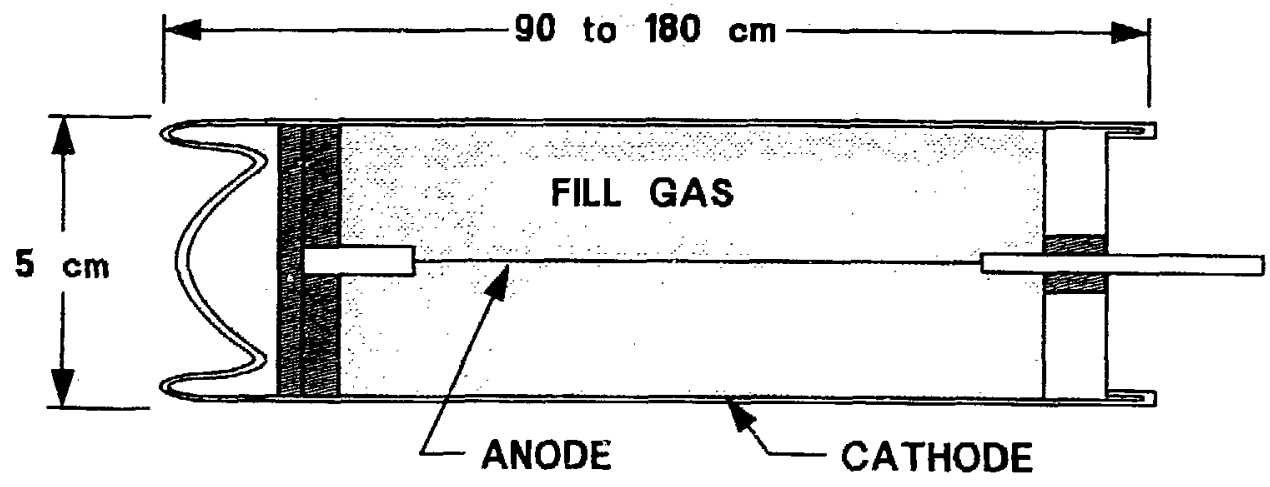

Fig. 16. Neutron proportional counters are thin metallic cylinders containing a converter gas to react with neutrons and produce ionizing radiation that can be detected. 

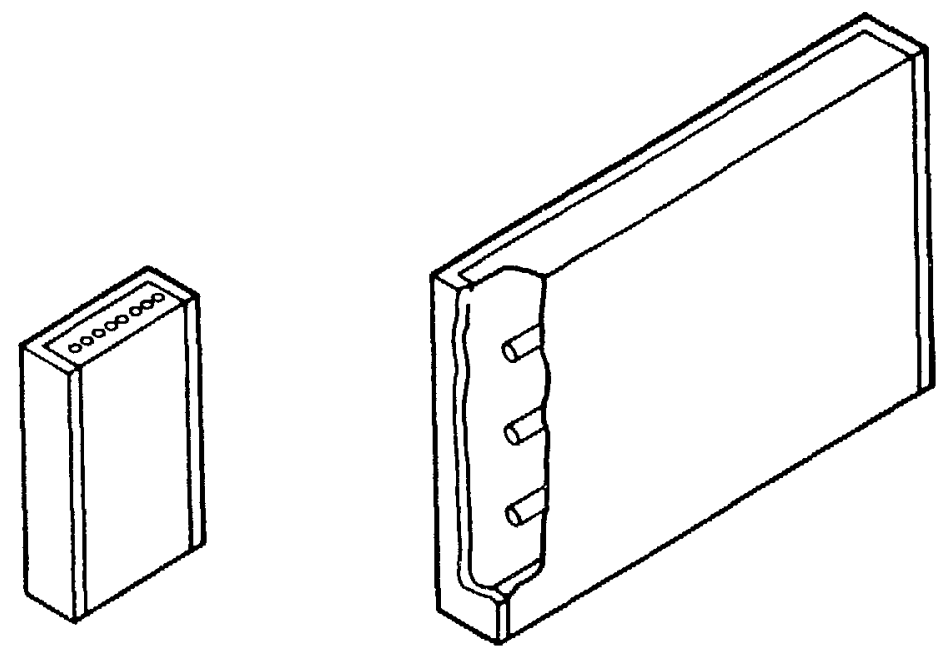

Fig. 17. Two common ways to moderate neutrons in a neutron detector. Left, proportional counters are embedded in solid polyethylene that provides moderation. Right, the counters are in a chamber formed by polyethylene walls that moderate neutrons and contain them.

$8 \%$ to $20 \%$ for fission-spectrum neutrons, a single layer of counters, and ${ }^{3} \mathrm{He}$ or $\mathrm{BF}_{3}$ counters. ${ }^{8,9}$

Shown at the right in Fig. 17 is another way to provide moderation: a hollow polyethylene-walled box forms a chamber enclosing just a few counters. The box moderates neutrons in its polyethylene walls; the moderated neutrons that enter the interior chamber may bounce around for a while and eventually be detected. Therefore, neutrons can have several chances to be detected and fewer proportional counters are needed. With only a few counters, this simply constructed neutron chamber detector can be made inexpensive and large enough to intercept many neutrons in a vehicle portal. The intrinsic detection efficiency of a Los Alamos prototype neutron chamber is about $8 \%$ for fission spectrum neutrons.

Both slab and chamber neutron detectors can be shielded by neutron-absorbing material on the edges and back to minimize neutron background. Each can be made with more than one layer of counters to improve its detection sensitivity. For instance, a double neutron chamber detector, one behind the other, has an intrinsic efficiency of about $15 \%$, and a two-layer slab may have efficiency up to about $30 \%$. To compare the performance of these neutron detectors in a vehicle portal monitor, we designed and evaluated two equal-cost detector units, a neutron chamber and a slab.

a. A Neutron Chamber Portal Monitor. The most cost-effective neutron proportional counter is a ${ }^{3} \mathrm{He}$ counter $5 \mathrm{~cm}(2 \mathrm{in}$.) in diameter by $183 \mathrm{~cm}(6 \mathrm{ft})$ long, which costs about $\$ 2100$. Four of these at a cost of $\$ 8400$ per detector are used in a chamber having exterior dimensions of 122 by $244 \mathrm{~cm}(4$ by $8 \mathrm{ft}$ ) and a depth of $15 \mathrm{~cm}(6 \mathrm{in}$.). The front surface of the chamber is formed of polyethylene $1.25 \mathrm{~cm}(0.5 \mathrm{in}$.) thick, and the back and side surfaces are polyethylene $5 \mathrm{~cm}(2$ in.) thick. The different polyethylene thicknesses help the detector to respond well to SNM that is bare and SNM that has moderator or neutron shielding material around it. An additional layer of borated polyethylene $2.5 \mathrm{~cm}$ (1 in.) thick on the back and sides reduces the detector's background count rate. One of these chamber detectors can be placed at each side of a roadway $6 \mathrm{~m}(20 \mathrm{ft})$ wide, for example, to form a vehicle portal monitor.

b. A Neutron Slab Portal Monitor. The slab detector has $16 \mathrm{BF}_{3}$ proportional counters $5 \mathrm{~cm}(2$ in.) in diameter by $91 \mathrm{~cm}(3 \mathrm{ft})$ long embedded in a solid

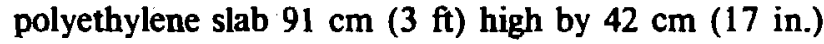
wide. The cost of the proportional counters is $\$ 650$ each for a total of $\$ 10,460$ per slab. The proportiona' counters are adjacent to one another and have $1-\mathrm{cm}$ thick polyethylene at the front and 5-cm-thick polyethylene and 1-cm-thick borated polyethylene at the back and sides, the same as for the chambers described above. Two slab detectors, one at each side of the roadway, form a vehicle portal monitor.

To compare the performances of the two detectors, we measured their background count rates and their source response to a standard fission neutron source at a typical midroad distance of $3 \mathrm{~m}$. Then we calculated a figure of merit for each as used on one side of a $6-\mathrm{m}$ wide roadway where a fission source emitting $10,000 \mathrm{n} / \mathrm{s}$

\footnotetext{
* $\mathrm{Had} \mathrm{BF}_{3}$ counters not been already available, we could have used ${ }^{3} \mathrm{He}$ proportional counters as well. Half as many counters at equal cost should provide equal performance.
} 
has to be detected $50 \%$ of the time. This neutron source corresponds to the one being detected in the lowest curve in Fig. 14 at $5-\mathrm{cm}$ lead thickness. The basic information for each detector type is listed in Table IV.

The figure of merit in the final column of Table IV is a measure of the detection sensitivity of an individual detector operating in a vehicle portal; it relates the net signal from a particular source to the square root of the expected background, which is the standard deviation of background. Generally, values of at least 4 are required for detecting a particular source in a monitor operating at an acceptable statistical false-alarm rate. Hence, one of the neutron chamber detectors might provide adequate performance for detecting the $10,000-\mathrm{n} / \mathrm{s}$ source at a 3-m distance, but the slab would not.

The 6-m-wide roadway requires a detector at each side to detect this source anywhere in the roadway. To follow up this example, Table $\mathrm{V}$ lists the information for portals having two detectors and making a series of 2-slong monitoring counts during vehicie passage. The slab still has a less-than-optimum figure of merit. On the other hand, the chamber detector portal has a detection probability for the $10,000-n / s$ source of $99.9 \%$ at a falsealarm probability per test of 0.0001 . The latter value corresponds to 1 false alarm per 1500 passages if an average of 6 tests are made per vehicle passage.
3. A Prototype Neutron Vehicle Portal Monitor. The better performance estimate for the neutron chambers led us to use them in a prototype neutron vehicle portal. The comparison summarized in Table $\mathrm{V}$ leads us to believe that performance equal to that of the monitoring station for detecting SNM in 5-cm-thick lead can be achieved in a vehicle portal with neutron chamber detectors. We realize that equal performance at higher cost might be obtained with slab detectors if small detectors are important for some reason. In fact, we verified that monitoring signals for SNM passing in a vehicle are similar in portals employing either detector type even though the detectors differ in size. In our case, having no size restriction and wanting to develop a minimum-cost, high-performance monitor, we chose to use the neutron chamber.

Our prototype neutron vehicle portal monitor has two neutron chamber detectors (Fig. 18) positioned beside the roadway. Its signal-conditioning and control electronics circuits are located in a nearby climatecontrolled electronics cabinet. Standard NIM preamplifiers, amplifiers, and power supplies are used. The amplifier is modified to extend its shaping time to about $15 \mu$ s to avoid double pulsing. The control functions take place in the custom NIM neutron-portal controller (Fig. 19). The controller is designed to operate

\begin{tabular}{|c|c|c|c|c|c|}
\hline \multirow[b]{2}{*}{$\begin{array}{c}\text { Detector } \\
\text { Type } \\
\end{array}$} & \multicolumn{5}{|c|}{ Detector Characteristics } \\
\hline & $\begin{array}{c}\text { Intrinsic } \\
\text { Efficiency } \\
(\%)\end{array}$ & $\begin{array}{l}\text { Sensitive } \\
\text { Area } \\
\left(\mathrm{cm}^{2}\right) \\
\end{array}$ & $\begin{array}{l}\text { Background" } \\
\text { Count Rate } \\
\text { (counts/s) }\end{array}$ & $\begin{array}{l}\text { Net Source } \\
\text { Count Rate } \\
\text { (counts/s) }\end{array}$ & $\begin{array}{l}\text { Figure } \\
\text { of } \\
\text { Merite }\end{array}$ \\
\hline $\begin{array}{l}\text { Slab } \\
\text { Chamber }\end{array}$ & $\begin{array}{r}16.6 \\
8.4\end{array}$ & $\begin{array}{r}3720 \\
29700\end{array}$ & $\begin{array}{r}9.5 \\
26.9 \\
\end{array}$ & $\begin{array}{r}5.5 \\
21.3 \\
\end{array}$ & $\begin{array}{l}2.5 \\
5.8\end{array}$ \\
\hline \multicolumn{6}{|c|}{$\begin{array}{l}\text { "Background is for a } 2100-\mathrm{m}(6900-\mathrm{ft}) \text { altitude. } \\
\text { The source is } 3 \mathrm{~m} \text { from the center of each detector. } \\
\text { 'The figure of merit is the net source count divided by the square rovt of background for } \\
\text { a count } 2 \mathrm{~s} \text { long. }\end{array}$} \\
\hline
\end{tabular}

TABLE V. Basic Information for Two Neutron Vehicle Portals

\begin{tabular}{|c|c|c|c|c|c|}
\hline \multirow[b]{2}{*}{ Detectors } & \multicolumn{2}{|c|}{ Detector Characteristics } & \multicolumn{3}{|c|}{ Monitor Characteristics } \\
\hline & $\begin{array}{l}\text { Background } \\
\text { Count Rate } \\
\text { (counts/s) }\end{array}$ & $\begin{array}{c}\text { Net Source } \\
\text { Count Rate } \\
\text { (counts/s) }\end{array}$ & $\begin{array}{c}\text { Total } \\
\text { Background } \\
\text { (counts) }\end{array}$ & $\begin{array}{c}\text { Total }^{b} \\
\text { Net Signal } \\
\text { (counts) }\end{array}$ & $\begin{array}{c}\text { Figure }^{c} \\
\text { of } \\
\text { Merit }\end{array}$ \\
\hline Two slab & 9.5 & 5.5 & 38 & 22.0 & 3.6 \\
\hline Two chamber & 26.9 & 21.3 & 107.8 & 85.2 & 8.2 \\
\hline
\end{tabular}




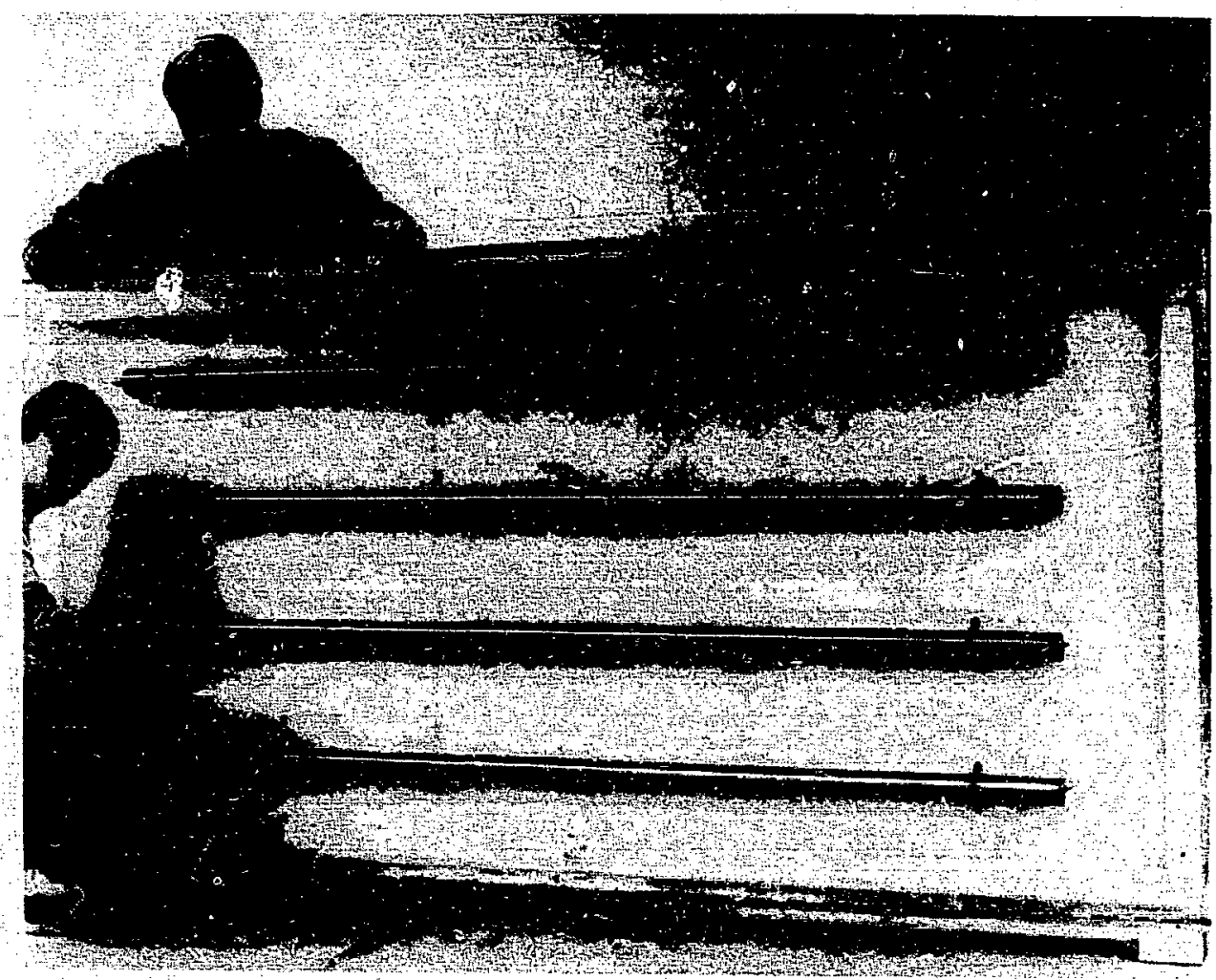

Fig. 18. Each neutron chamber detector is a polyethylene-lined space containing four ${ }^{3} \mathrm{He}$ proportional counters. Its large size is an important contribution to its effectiveness.

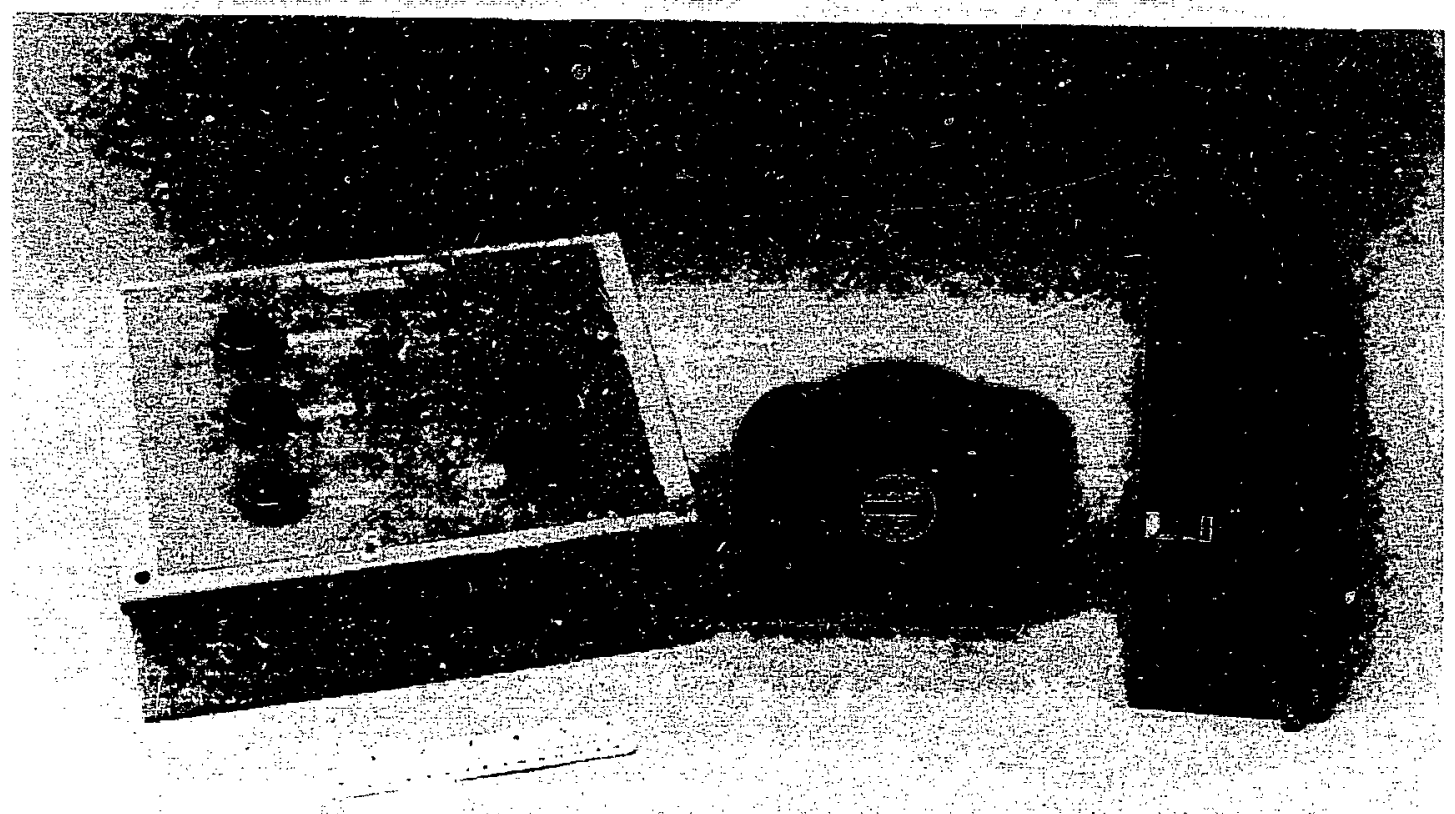

Fig. 19. The neutron portal control system uses sequential testing to detect neutron emitters. It has teletype input and output, a rems information and control unit, and a speaker for computer-generated vocal information. 
at very low count rates, and its decision logic is based on a sequential probability ratio method applied to Poisson-distributed counts. The sequential probability ratio technique is described further in Sec. II.

At this time, we are evaluating the neutron vehicle portal monitor for routine monitoring. We hope to incorporate any needed changes into more compact, battery-operated elecironics that can be housed in the detector cabinets themselves. That should greatly reduce the cost of the monitor by eliminating the need for the electronics cabinet, the air conditioner, and most interconnecting wiring. Once we have completed this step, we hope to commercialize the neutron vehicle portal.

\section{SEQUENTIAL ANALYSIS FOR MONITOR- ING DECISIONS}

All automatic SNM monitors must detect significant intensity increases in radiation detectors that have a background from natural gamma-ray and neutron radiation. Detection results from a decision after comparing each monitoring measurement with the expected result for background intensity. An alarm decision results when a monitoring measurement exceeds the expected background result by an amount (alarm level) that will limit the chance for a statistical false alarm to less than one in a few thousand passages of a pedestrian or vehicle through an automatic SNM monitor. Monitors may make one or several decisions during a passage; vehicle portals make six or more separate decisions, a monitoring station only one.

Making fewer decisions per passage would allow the alarm level to be reduced because the statistical alarm rate is the statistical alarm probability times the decisis rate. However, in monitoring stations, that lower alarm level still requires counting times of a minute or more to achieve detection sensitivity similar to that of pedestrian monitors. Reference 2 describes a method to shorten that counting time by making preliminary decisions at lower alarm levels that have high false-alarm probability. A preliminary decision to alarm simply continues monitoring up to a maximum time when a decision must be made. A preliminary decision for background at one-third or two-thirds of the singleinterval length terminates monitoring. This method maintains detection sensitivity but permits all but $4 \%$ of the background decisions to be made in one-third the single-interval monitoring time. The sequential probability ratio decision method has similar properties.

We describe the sequential method in Ref. 6 and its application to the vehicle monitoring station in Ref. 10 . The approach is to divide the normal monitoring time into subintervals of time, after which an intermediate decision is made to terminate or to continue monitoring. Two decision thresholds are used, one for background and one for alarm; and if neither decision can be made, monitoring continues unless the maximum allowed time is reached. If a decision cannot be made in the maximum allowed time, then an alarm is sounded. The decision threstrolds are selected to achieve the same detection sensitivity and false-alarm probability as the single-interval test that is replaced.

The sequential decision method benefits from its ability to end monituring as soon as it reaches a decision (thereby shortening a verage monitoring time) and from its use of the probability ratio to make decisions. The probability ratio test is an optimal decision method that minimizes the required number of steps. Each probability ratio is the ratio of the probability of observing a count in a source plus background count distribution to the probability of observing it in a background distribution. As monitoring proceeds, the accumulated step probability ratios are multiplied together and compared with decision thresholds. The thresholds are chosen to achieve the same detection and statistical alarm probabilities as for a single-interval test over the maximum time. For background alone or for a strong source, the sequential method makes rapid decisions. Just at the threshold for detection, a longer time is required that is limited to the maximum time.

We have implemented the sequential method in the vehicle monitoring station design. The method is applied to four independent monitoring channels used for the four separate groups of detectors. The controller (Fig. 13) monitors with 4-s-long steps. Its maximum monitoring time is $60 \mathrm{~s}$. Its average monitoring time at background intensity is about $20 \mathrm{~s}$. The distribution of monitoring times with source intensity is plotted in Fig. 20. In routine operation, the detectors see less than background intensity by one or two standard deviations when vehicles are present to attenuate background radiation. In this case the decisions are made rapidly.

The rapid decision capability of the sequential technique also makes it useful in vehicle portal monitors. Counting times for vehicle portals may be about $2 \mathrm{~s}$. One optimum method for SNM detection can use a moving average of 0.5 -s counts forming a series of 2-slong sums for analysis. Perhaps six of the sums will be analyzed during passage of a vehicle. The moving average starts when the vehicle is sensed at a random position relative to the SNM, but one of its sums will eventually contain the most intense part of any signal from SNM. The sensitivity of the method is as high or higher than that of other methods even though a slightly higher alarm level is needed to maintain a singleinterval false-alarm rate. The sequential technique duplicates this optimum performance with its ability to make rapid decisions at or below background intensity. When intensity begins to increase significantly, its next 


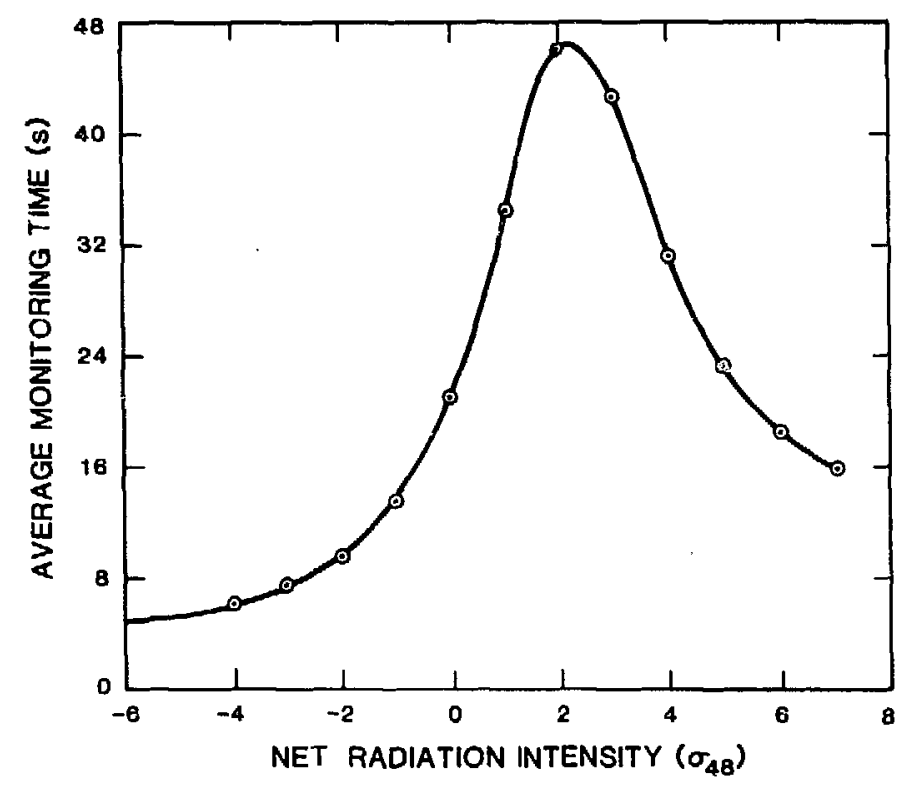

Fig. 20. The average monitoring time with the sequential method is low except at the threshold for detection. The intensity units are the standard deviation of a 48-s count.

decision takes longer; its final decision is delayed until the the maximum signal has been counted.

We developed a vehicle portal monitor controller using the sequential method and found it to be as effective as one applying the moving average. ${ }^{11}$ Another benefit of this controller is that it can be used in a variety of applications. It can operate pedestrian monitors for walk-through or stationary monitoring, and it can operate vehicle monitors with a variety of portal widths and passage speeds by making simple changes in its operating parameters. The parameters are modified through teletype input, a simple user modification that adapts the monitor to a variety of applications.

\section{HAND-HELD MONITORS WITH NEUTRON SENSITIVITY}

Hand-held monitors normally use $\mathrm{NaI}(\mathrm{Tl})$ for its high intrinsic detection efficiency that permits using small detectors and for its photoelectric response to gamma rays that permits using low-gain electronic circuits for signal conditioning. Unfortunately, NaI(Tl) lacks neutron sensitivity and is unable to detect plutonium inside thick gamma-ray shielding. One commercially manufactured hand-held monitor, the TSA Systems*
HHD-440, uses a plastic scintillator that responds to both gamma rays and neutrons and is more suitable for detecting gamma-ray-shielded plutonium. The drawback to this monitor is its weight, about $3 \mathrm{~kg}(6.6 \mathrm{lb})$, which limits its usefulness for hand-held monitoring.

As an example of the difference in neutron sensitivity for the two detector types, Table VI lists the responses of two hand-held monitors to a plutonium source in different thicknesses of lead shielding. The behavior is much like what we observe in vehicle monitoring stations. The plastic scintillator continues to respond to a residual neutron signal when plutonium is heavily shielded.

Each monitor in Table VI has adequate count rate to detect t] source readily at $2.5-\mathrm{cm}$ lead thickness, but only the plastic one detects it at the $5-\mathrm{cm}$ thickness. Notice that at the 5-cm thickness, the $\mathrm{NaI}(\mathrm{Tl})$ detector can neither detect the source nor produce a count rate above background. This inability is a result of the shield partially excluding the detector's view of the ambient background radiation.

The effectiveness of the plastic scintillation detector prompted us to adapt it to a lighter hand-held monitor. We replaced the $\mathrm{NaI}(\mathrm{Tl})$ detectors with plastic scintillators in two Los Alamos designed lightweight monitors manufactured for us by TSA Systems* as
TSA Systems, Inc., 4919 North Broadway, Boulder, CO 80302 , (303) 447-8553.
-TSA Systems, Inc., 4919 North Broadway, Boulder, CO 80302, (303) 447-8553. 


\begin{tabular}{|c|c|c|c|c|}
\hline \multirow[b]{2}{*}{$\begin{array}{c}\text { Detector } \\
\text { Type }\end{array}$} & \multirow[b]{2}{*}{$\begin{array}{c}\text { Background" } \\
\text { (counts/s) }\end{array}$} & \multicolumn{3}{|c|}{ Lead-Shielded-Source Response ${ }^{b}$ (counts/s) } \\
\hline & & $\begin{array}{c}1.25 \mathrm{~cm} \\
\text { Thick }\end{array}$ & $\begin{array}{l}2.5 \mathrm{~cm} \\
\text { Thick }\end{array}$ & $\begin{array}{l}5 \mathrm{~cm} \\
\text { Thick }\end{array}$ \\
\hline $\begin{array}{l}\text { NaI(TI) } \\
\text { Plastic }\end{array}$ & $\begin{array}{r}70 \\
384\end{array}$ & $\begin{array}{r}285 \\
1300\end{array}$ & $\begin{array}{l}100 \\
630\end{array}$ & $\begin{array}{r}57 \\
470\end{array}$ \\
\hline
\end{tabular}

model PRM-470. One version has the plastic scintillator positioned against the bottom of its case (Fig. 21), and the other has the detector against the front of the case. Each detector is rectangular. Two different positions are used for the photomultiplier tube: one is attached to the scintillator edge (Fig. 21) and the other to the scintillator face. These modified units weigh $1.6 \mathrm{~kg}(3.6 \mathrm{lb})$, which is about $55 \%$ of the HHD-460 weight and $43 \%$ more than that of the original prototype. Preliminary performance trials with the modified units duplicate the HHD-440 performance for detecting shielded and unshielded plutonium and show only slightly less sensitivity for detecting HEU than do the original $\mathrm{NaI}(\mathrm{Tl})$ detector units. This agrees with our earlier work on the relative performance of small radiation detectors. ${ }^{12} \mathrm{We}$ are conducting a thorough evaluation of the modified units as operational hand-held monitors.

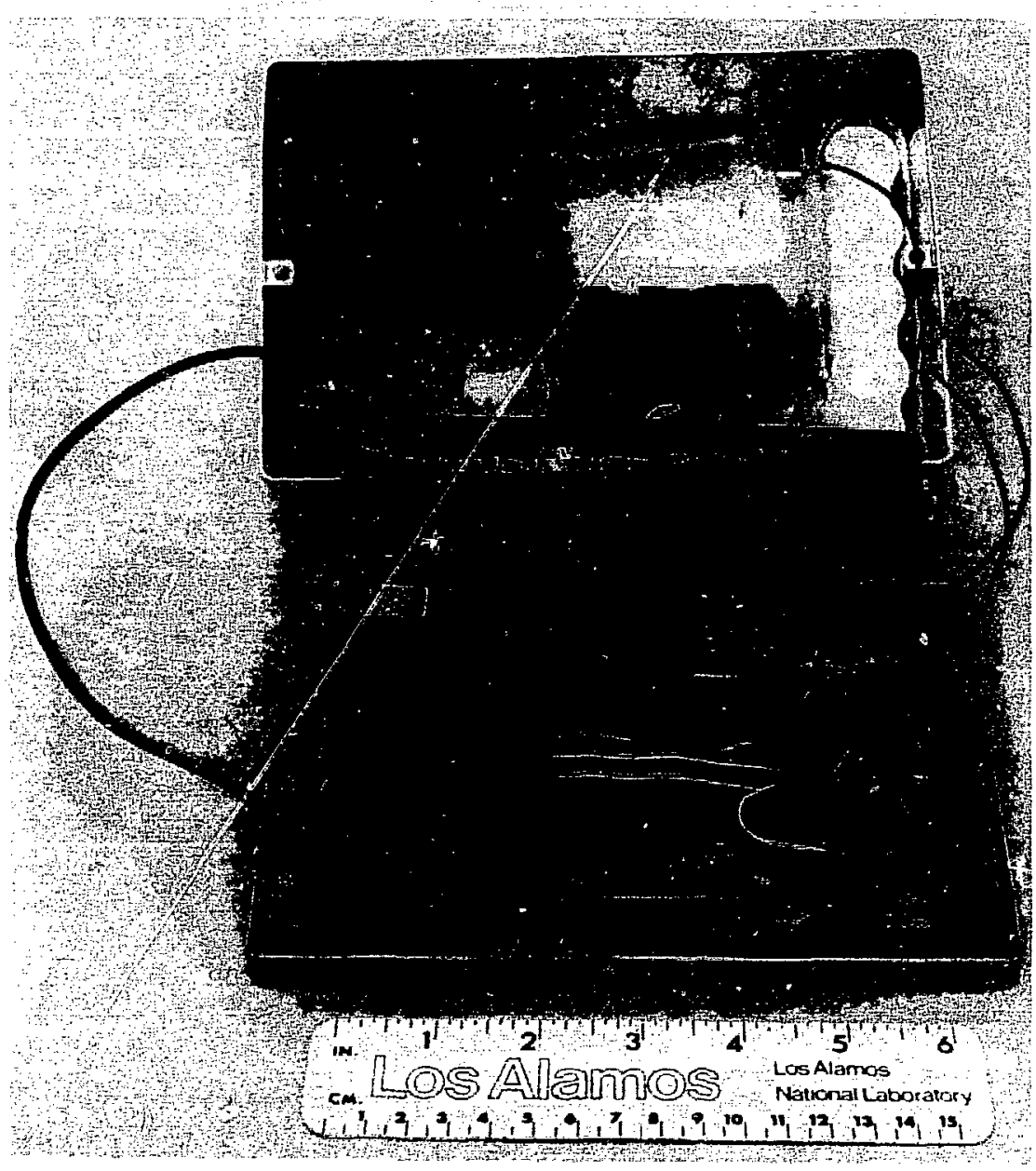

Fig. 21. The modified PRM-4 70 hand-held monitor now has a plastic scintillation detector to provide gamma-ray and neutron response. 


\section{PART 3}

\section{A CATALOG OF VEHICLE SNM RADIATION MONITORS*}

This part briefly describes each vehicle SNM radiation monitor that has come into use in recent years. Elementary monitors are included as well as improved high-sensitivity monitors that are now commercially available or are in the latter stages of development. One vehicle monitor manufactured and commercially available in France is the final catalog entry.

The vehicle SNM monitors described here fall into three basic types: hand held, vehicle portal, and vehicle monitoring station. Each type of monitor has unique capabilities, and within each type there is undoubtedly some variation in capability. Where an impartial evaluation of the monitor has taken place, the results are mentioned. Otherwise, the monitor's capability can be taken only from the manufacturer's literature or inferred from comparison of its detectors with ones for which information is tabulated in Part 1 . We have included performance estimates for the common radioisotopes ${ }^{138} \mathrm{Cs}$ and ${ }^{60} \mathrm{Co}$ when available. Note that the first emits one $662-\mathrm{keV}$ gamma ray in each disintegration, whereas the second emits two gamma rays with average energy of $1225 \mathrm{keV}$ in each disintegration. As a result, minimum detectable quantities of ${ }^{137} \mathrm{Cs}$ are usually about double the minimum detectable quantities of ${ }^{60} \mathrm{Co}$.

The business address for each manufacturer is listed. Further information on individual monitors is available from the manufacturer or from the author.* Detailed specifications for purchase of monitors developed by Los Alamos are also available from the author.

*Paul E. Fehlau, Los Alamos National Laboratory, MS J562, Los Alamos, NM 97545, (505) 667-5372 or FTS 843-5372.
-Reference herein to any specific commercial product, process, or service by trade name, trademark, or manufacturer does not necessarily constitute or imply its endorsement, recommendation, or favoring by the United States Government or agency thereof. 


\section{HAND-HELD VEHICLE SNM RADIATION MONTTORS}

These small, battery operated, hand-held SNM monitors were individually described in the pedestrian SNM monitor guide.' Since then, Los Alamos has commercialized its lightweight hand-held monitor, the Los Alamos Programmable Radiation Monitor, as the TSA Systems* PRM-470 shown at the center below. This monitor and the one to the left, the HM-3 from $\mathrm{Na}$ tional Nuclear Corp., ${ }^{*}$ or DRM-2 from CMS, Inc., $\dagger$ have $\mathrm{NaI}(\mathrm{Tl})$ detectors whereas the one at the right, the TSA Systems HHD-440, has a plastic scintillation detector useful for gamma-ray or neutron monitoring.

Each monitor employs digital electronics to measure ambient background intensity and to detect small in-

-TSA Systems, Inc., 4919 North Broadway, Boulder, CO 80302, (303) 447-8553.

* National Nuclear Corp., 1904 Colony Street, Mountain View, CA 94043, (415) 962-9220.

†CMS, Inc., 6446 Caroldale Place, Goleta, CA 93117, (805) 964-7451. creases near SNM. The instruments serve as a back-up for automatic vehicle monitors or in some cases as the primary means to search vehicles for SNM. They also are used for health physics monitoring of vehicles that may be contaminated with gamma-ray emitters. The monitors have rechargeable batteries that permit operation for different periods of time. The longest operating period is $48 \mathrm{~h}$ for the PRM-470; the shortest period is $8 \mathrm{~h}$ for the HHD-440. Overnight recharging is recominended as needed. Continuous charging is discouraged.

The performance of each of these monitors has bren verified in a test against performance standards once used by DOE. ${ }^{13}$ The test protocol required detecting a 10-g metallic sphere of HEU and a $1-\mathrm{g}$ metallic sphere of recently separated low-burnup plutonium. Each test source must be detected as it moves past the detector at $0.5 \mathrm{~m} / \mathrm{s}$ at a distance of $0.25 \mathrm{~m}$ in an environment having a background intensity of $20 \mu \mathrm{R} / \mathrm{h}$. At the same speed and approach distance, these instruments detect less than $1 \mu \mathrm{Ci}$ of ${ }^{137} \mathrm{Cs}$.

Costs of hand-held monitors range from $\$ 1400$ to $\$ 2000$, but the lowest priced ones have smaller detectors that may limit sensitivity. Prices for the monitors with appropriately sized $\mathrm{NaI}(\mathrm{Tl})$ scintillators are nearly the same.

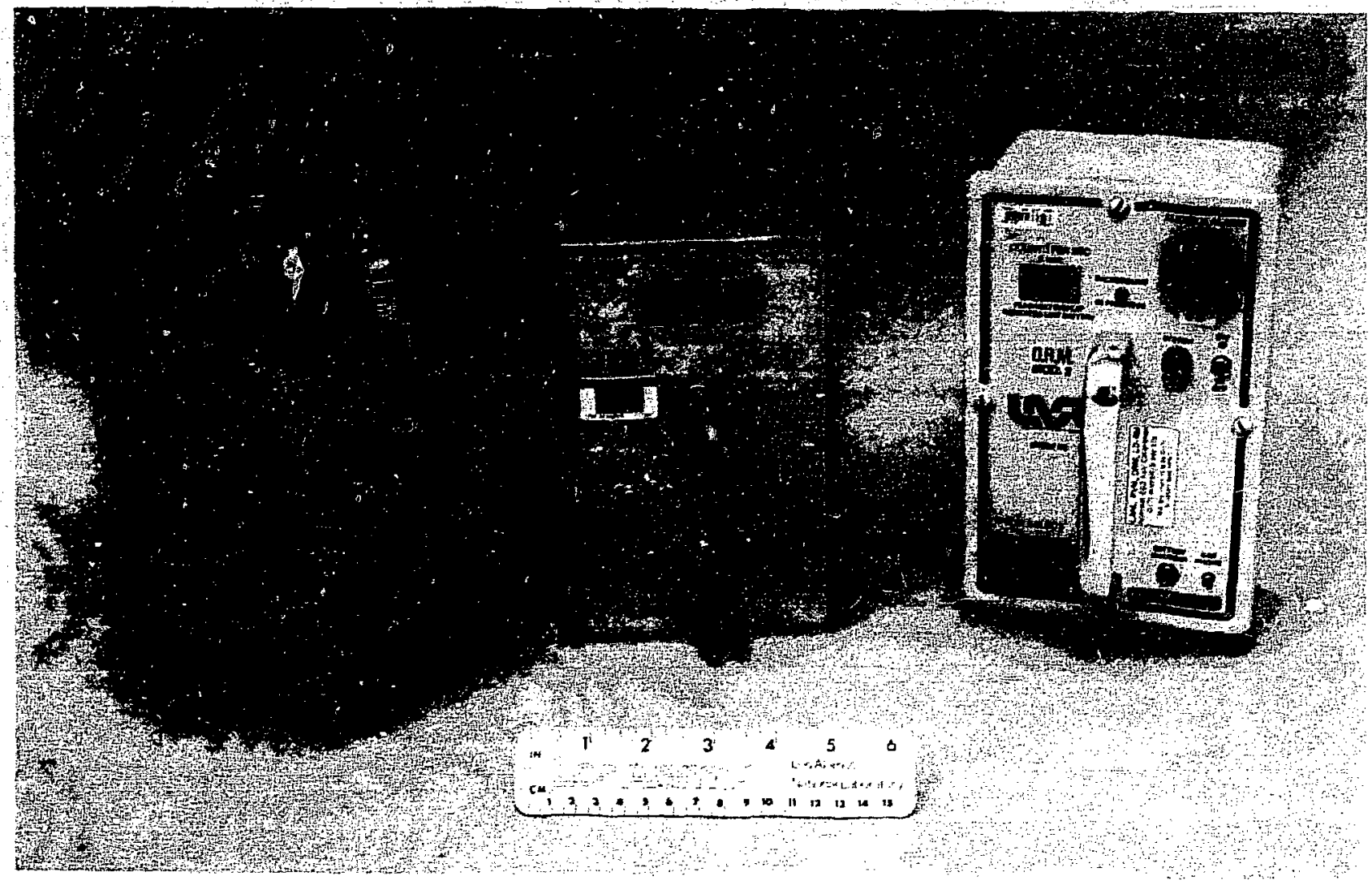




\section{TSA SYSTEMS* VM 106 VEHICLE PORTAL MONITOR}

One of the earliest automatic vehicle SNM monitors, the TSA Systems VM 106 vehicle portal monitor emerged as a commercial product not long after the concept of a vehicle SNM portal monitor was developed at the DOE Rocky Flats plant in the early 1970s. The VM 106 uses four small NaI(Tl) detectors,

TSA Systems, Inc., 4919 North Broadway, Boulder, CO 80302, (303) 447-8553. two in each cabinet beside the gate. The VM 106 control unit was one of the first with digital electronics that automatically measures background intensity and calculates an alarm level from the results. Monitoring measurements are analyzed with a simple, singleinterval test that is repeated as long as a vehicle is present. Although this monitor is no longer marketed, some of the monitors are still being used.

The advertised detection sensitivity for this monitor

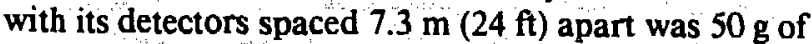
plutonium oxide having $12 \%{ }^{240} \mathrm{Pu}$ content when the monitor was operated at a false-alarm rate of about 1 per 1200 vehicle passages. The background intensity was not specified.

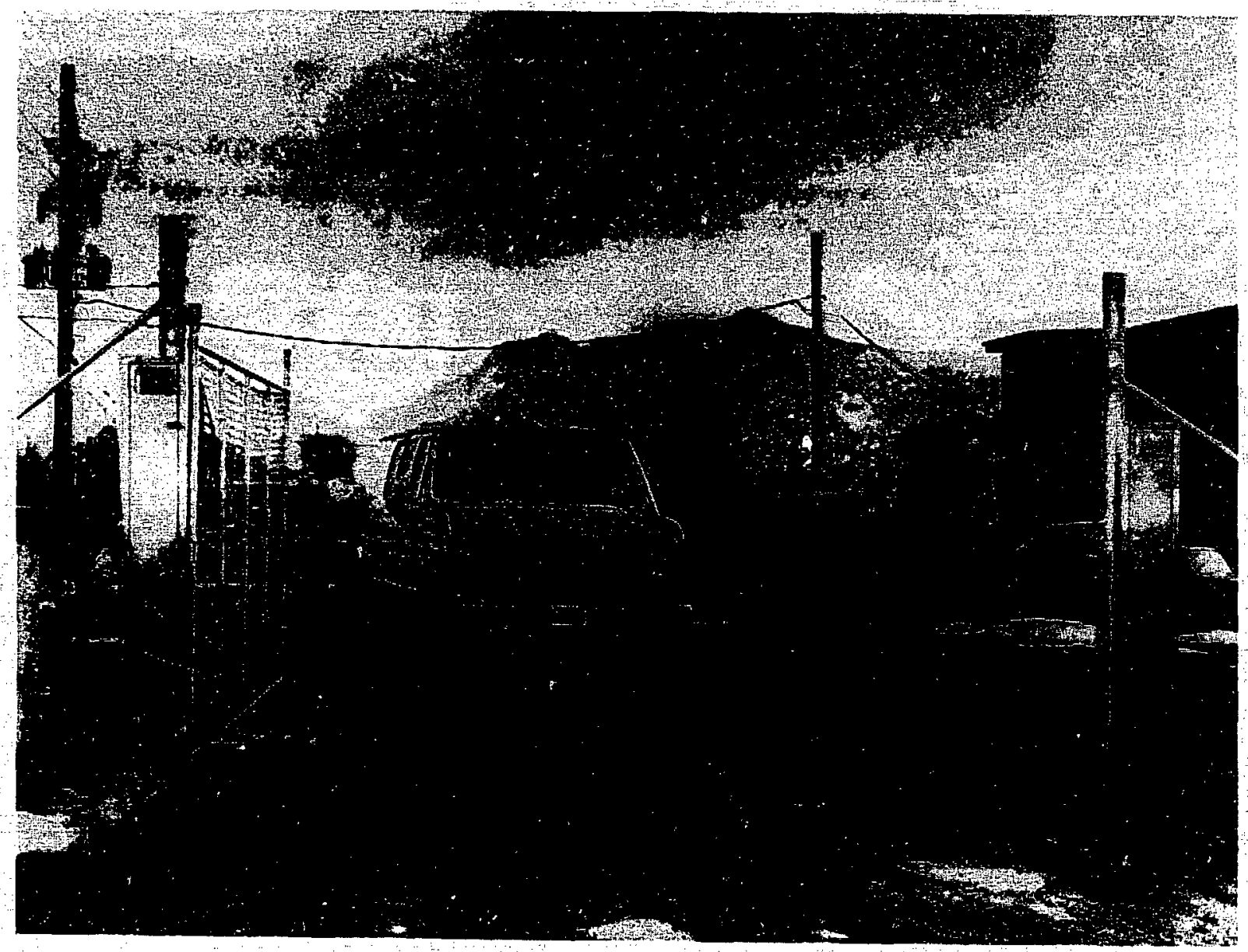




\section{LOS ALAMOS ENTRY-CONTROL MONITOR}

Developed for the US Navy, the Los Alamos EntryControl Monitor is a vehicle SNM portal monitor designed to detect the removal of SNM from military weapon stations. Its objective is to detect removal by vehicle of entire weapon assemblies containing SNM, a task well suited to the vehicle portal monitor. The monitor is commercially fabricated by TSA Systems, Inc., as the ECM-330.

The entry-control monitor has two detector cabinets $3 \mathrm{~m}(10 \mathrm{ft})$ tall positioned beside a gate and an airconditioned electronics cabinet located nearby. The spacing between detector cabinets is about $5 \mathrm{~m}(17 \mathrm{ft})$. Each detector cabinet contains two plastic scintillation detectors, each $7.6 \mathrm{~cm}$ ( 3 in.) wide by $3.8 \mathrm{~cm}$ (1.5 in.) deep and $91 \mathrm{~cm}$ ( $36 \mathrm{in}$.) long. A light pipe $12.7 \mathrm{~cm}(5 \mathrm{in}$. long between scintillator and photomultiplier makes the detector's response very uniform. The detector cabinets are actively cooled by circulating chilled water from a reservoir in the electronics cabinet. The cabinets are painted white as a passive measure to control tempera-

†SA Systems, Inc., 4919 North Broadway, Boulder, CO 80302, (303) 447-8553. ture. The electronics cabinet contains the detector electronics and the monitor's control module. A remote information panel in a nearby station informs the guard of the monitoring results.

The monitor has two vehicle detectors that use current loops spaced apart and buried in the roadway to sense vehicles. The monitor's controller uses the sequence of detecting vehicles to determine incoming and outgoing traffic. Usually, only outgoing traffic is monitored. Monitoring uses a moving average method having a 2-s count time divided into four subintervals. As long as a vehicle is passing through the portal, the monitor continues to accumulate 0.5 -s counts to replace the oldest count in the 2-s moving average. As each updated count becomes available, the value is compared with an alarm level 4 standard deviations above the average background. An alarm decision terminates monitoring and sounds an alarm. Otherwise, monitoring continues as long as a vehicle is in the portal.

Placing the monitor near the gate to the vehicle trap at the entry control facility ensures that traffic will be moving slowly when it is monitored. Exiting vehicles must stop for inspection soon after passing through the monitor so that vehicle passage speeds of $8 \mathrm{~km} / \mathrm{h}$ ( $5 \mathrm{mph}$ ) are not unreasonable. At these speeds, the detection sensitivity listed in Table II for worst-case conditions can be achieved at the indicated statistical alarm rate.

Cost of this monitor is about $\$ 35,000$.

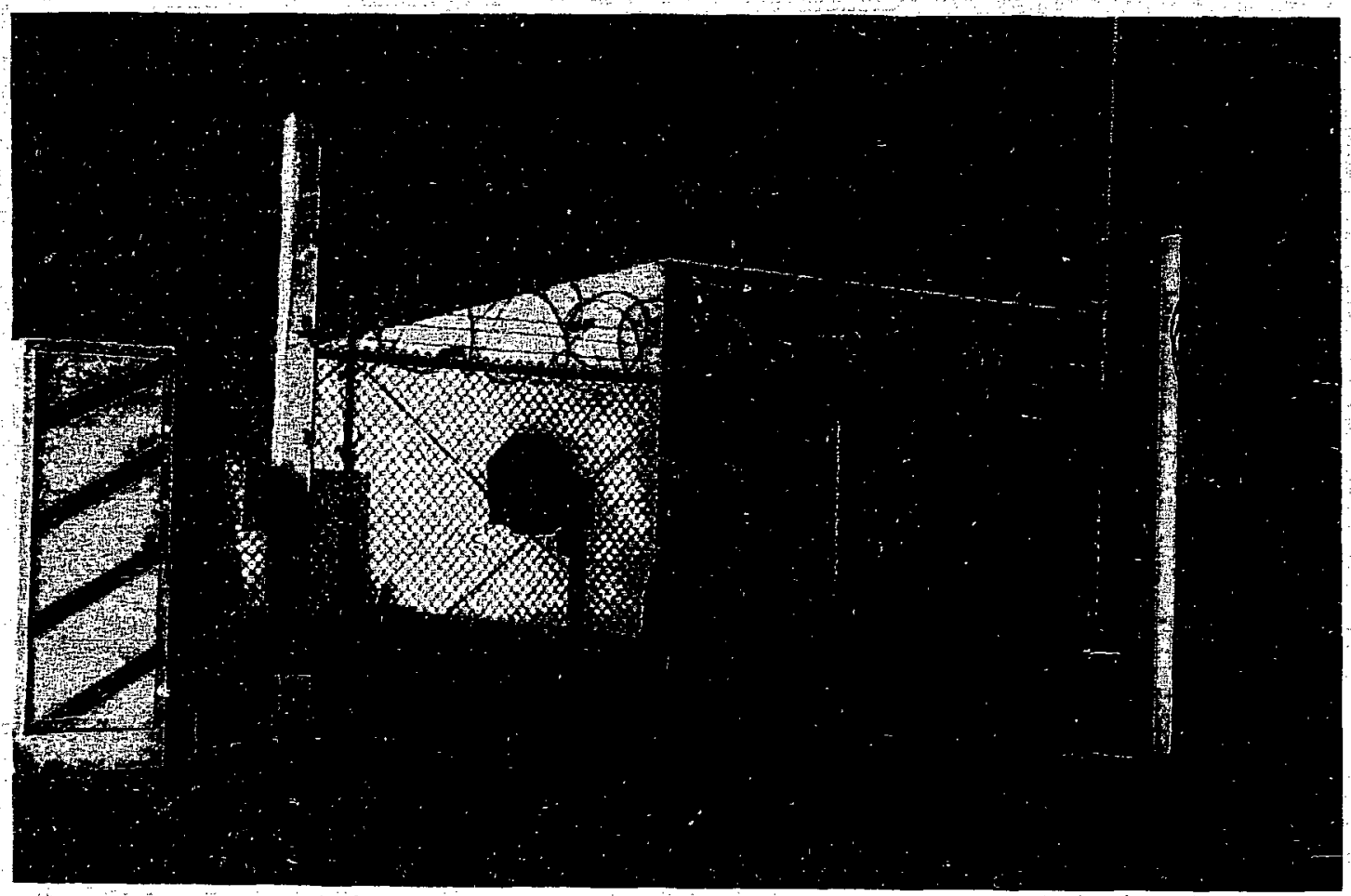




\section{LOS ALAMOS VEHICLE SNM PORTAL MONITOR}

Similar to the entry control monitor but somewhat more sensitive, the vehicle SNM portal monitor was developed for assembly areas at the Nevada Test Site. The task, an appropriate one for a vehicle portal monitor, requires monitoring SNM subassemblies.

The vehicle SNM portal monitor has two detector cabinets $3 \mathrm{~m}(10 \mathrm{ft})$ tall forming a portal, each cabinet containing two plastic scintillators $13 \mathrm{~cm}$ (5 in.) wide by $3.8 \mathrm{~cm}$ (1.5 in.) thick and $91 \mathrm{~cm}$ (36 in.) long. Each detector has a 13-cm (5-in.) light pipe. Each detector cabinet has two thermoelectric coolers, each of which is attached to a heat sink behind one of the photomultipliers. The heat sinks also have heating pads attached and thermostats to provide heating or cooling as appropriate at extreme temperatures. Near room temperature both heaters and coolers are inactive. Cabinets are painted white to minimize the amount of heating and cooling required.

An air-conditioned electronics cabinet located near one detector cabinet contains the signal-conditioning and control electronics. Vehicle sensors in the roadway inform the monitor's control module that a vehicle is present, at which time monitoring begins. Monitoring continues as long as the vehicle is in the monitor, and a sequential decision method is used to detect increased radiation intensity as a vehicle passes through. The control module has teletype input and output for setting operating parameters and for typing status information when required. One of the parameters allows using data temporarily stored before the vehicle was sensed so that any traffic sensor location can be used to begin monitoring. The monitor can be operated in a mode that lists all operating information on a teletype located in the electronics cabinet or in a mode that leaves the teletype inactive.

Monitoring information is communicated to the guard through a remote information module located in the guard station. Flashing lamps and a chime inform the guard when monitoring begins. Monitoring decisions are announced visually with lamps and audibly with an alarm sounder. An alarm reset button permits the guard to quiet the sounder.

Worst-case performance for the vehicle portal at $8 \mathrm{~km} / \mathrm{h}$ transit speed is listed in Table II. Its minimum sensitivity for ${ }^{137} \mathrm{Cs}$ is $9 \mu \mathrm{Ci}$ transported in a minimum attenuating vehicle passing through a portal $5.2 \mathrm{~m}$ (17 ft) wide at $8 \mathrm{~km} / \mathrm{h}(5 \mathrm{mph})$. The background intensity was $20 \mu \mathrm{R} / \mathrm{h}$.

The first NTS vehicle portal monitor was fabricated by Los Alamos and then duplicated by TSA Systems, Inc., as the VPM-333. The monitor's sequentialdecision-method control module, developed at Los Alamos and designated JNC-13, was produced by Jomar Systems, Inc., ** for both monitors.

Total cost for this monitor is about $\$ 40,000$.

*TSA Systems, Inc., 4919 North Broadway, Boulder, CO 80302, (303) 447-8553.

* Jomar Systems, Inc., 1143 18th Street, Los Alamos, NM 87544, (505) 662-9811.

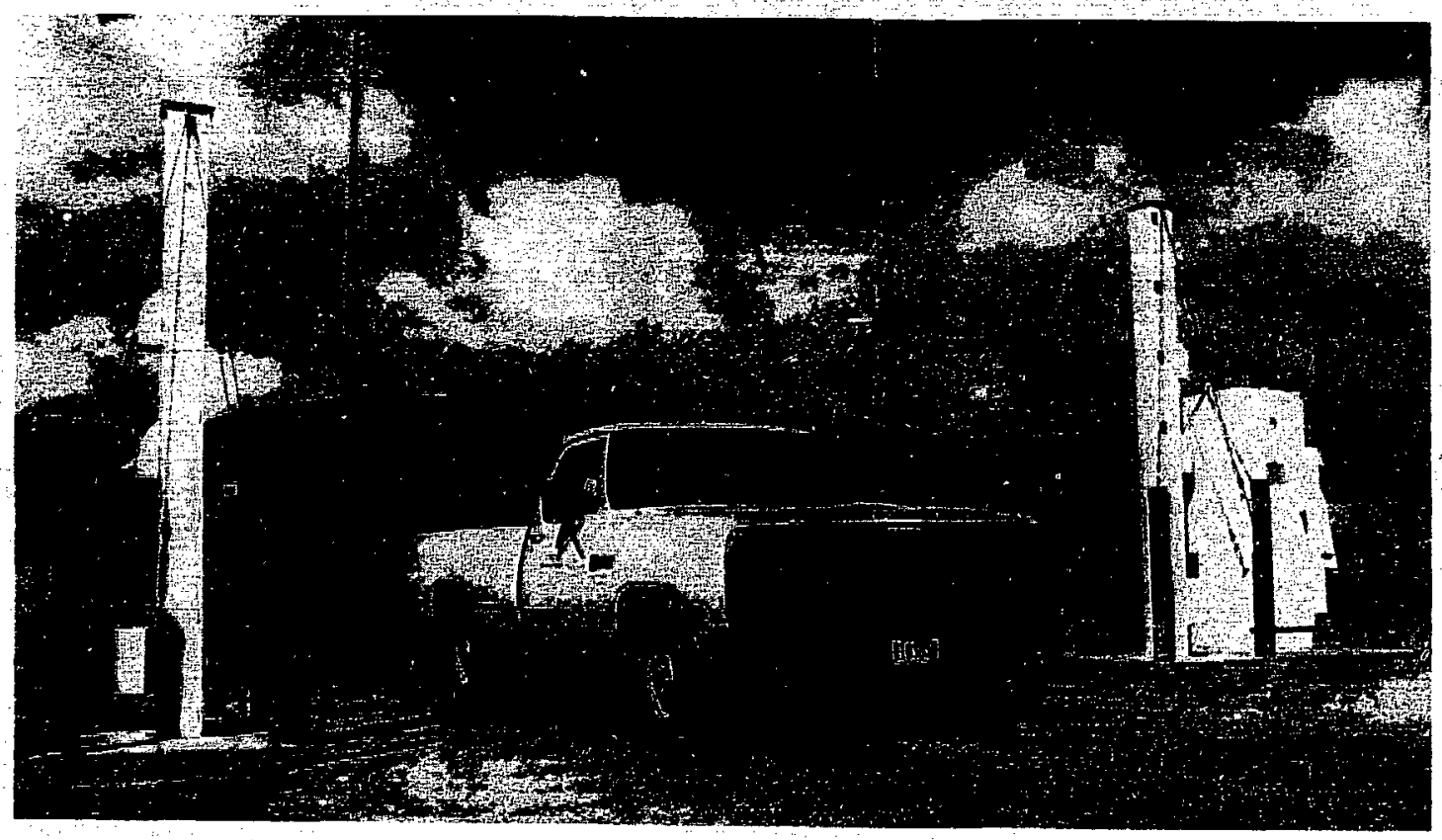




\section{TSA SYSTEMS VMC-250 VEHICLE PORTAL MONITOR}

A simplified form of vehicle portal monitor, the TSA Systems* VMC-250, evolved when TSA Systems merged vehicle-portal-monitor technology with handheld-monitor technology to make a cost-competitive product. The VMC-250 uses plastic scintillation detectors $13 \mathrm{~cm}$ ( 5 in.) wide by $3.8 \mathrm{~cm}$ ( 1.5 in.) thick and $79 \mathrm{~cm}$ (31 in.) long, similar to those in the Los Alamos vehicle portal, but operates them with a batterypowered electronics unit similar to their HHD-440, hand-held SNM monitor. Besides providing back-up power, a major advantage to trickle-charged battery operation of the electronics is that little heat is generated so that no air-conditioned electronics cabinet is required the electronics can be located in a detector cabinet. A second advantage in some cases, wide roadways for example, is that an electronics package can be used in each detector cabinet to make each cabinet an independent monitor.

Using the detectors at each side of a portal as an independent monitor lowers the portal sensitivity (for example, at the roadway center). The VMC-250 can sum all detector signals to achieve highest sensitivity when it is required. Another word of caution about the VMC-250 is that maintaining the compact batteryoperated electronics involves adjustments and test points on circuit-board-mounted components rather than adjustments of external calibrated-dial potentiometers and standard cable connectors. The complex maintenance problem can be overcome by hiring the manufacturer to provide routine, on-call maintenance and calibration service. Otherwise, to simplify mainte-

TSA Systems, Inc., 4919 North Broadway, Boulder, CO 80302 , (303) 447-8553. nance, special buffered outputs and external calibration adjustments should be requested from the manufacturer.

The VMC-250 uses vehicle sensors in the roadway, one in each traffic lane when detector cabinets are operated independently. When a vehicle is sensed, monitoring is continuous as long as the portal is occupied. The controller uses a moving average to maximize the signal count from passing radiation sources. Five 0.2 -s measurements, optimum for a $16-\mathrm{km} / \mathrm{h}$ (10-mph) single-lane passage speed, are averaged in the VMC-250 demonstration unit tested at Los Alamos. The controller has a liquid-crystal display that is visible through a cabinet wiıdow to display the monitor count rate. Audible and visible indicators transmit alarm information at a separate module located in the guard station.

A test unit having the VMC-250 controller and a single detector was evaluated at Los Alamos. Initial tests disclosed a high false-alarm rate from low-level electronic noise. The circuit board was redesigned to eliminate the problem; and further tests with the new design in January 1985 verified normal statistical performance. The single detector that we evaluated had a relatively high bias level of $100 \mathrm{mV}$, but it achieved about $85 \%$ of the maximum expected intrinsic detection sensitivity. The background intensity was $20 \mu \mathrm{R} / \mathrm{h}$. The single detector should detect about $9 \mu \mathrm{Ci}$ of ${ }^{60} \mathrm{Co}$ in a minimum-attenuating vehicle passing at $8 \mathrm{~km} / \mathrm{h}$ $(5 \mathrm{mph})$ at a $2.6-\mathrm{m}$ (8.5-ft) distance between source and detector.

We can estimate the worst-case sensitivity for a 5-mwide portal and an $8-\mathrm{km} / \mathrm{h}$ passage speed in terms of the Table II value. If all four detector signals are summed in a 5-m-wide portal, the worst-case minimum detectable mass is about $15 \%$ greater than the tabulated value. Independent detector pairs sense a $45 \%$ larger minimum detectable mass at roadway center. In either case, the monitor is an effective vehicle portal.

Cost of this monitor is about $\$ 20,000$.

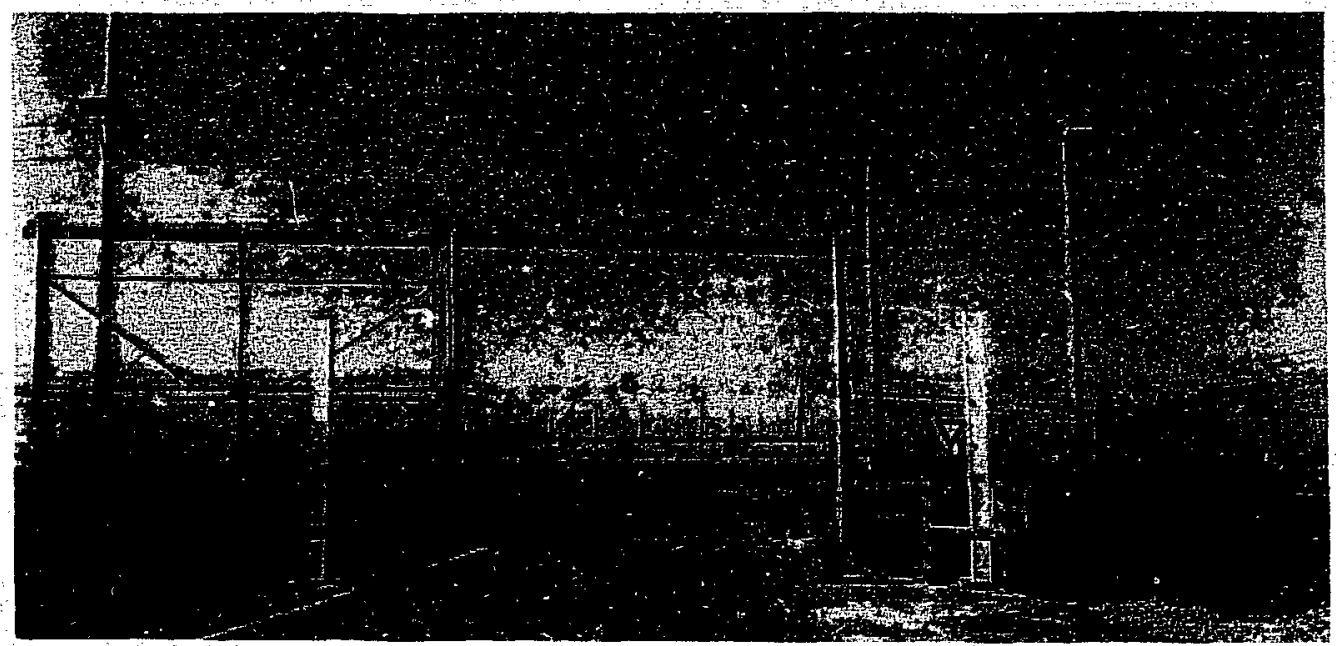




\section{LOS ALAMOS VEHICLE SNM MONITOR- ING STATION}

The highest detection sensitivity of all vehicle monitors is achieved in the vehicle monitoring station by using long counting times and many radiation detectors to monitor stationary vehicles. Counting times average $20 \mathrm{~s}$ but can extend to $1 \mathrm{~min}$ when sources near the threshold for detection are present. The 16 plastic scintillation detectors are positioned around the vehicle in 4 independent monitoring groups. The detectors are gamma ray and neutron sensitive. This type of vehicle monitor is the only one with detection sensitivity close to pedestrian SNM monitor sensitivity.

The Los Alamos vehicle SNM monitoring station is commercially fabricated by Jomar Systems, Inc., ${ }^{*}$ to a Los Alamos specification. The monitor has belowground plastic scintillation detectors housed in six cabinets spaced across the roadway on 1.2-m (4-ft) centers. Overhead are four plastic scintillation detectors in individual cabinets, each positioned over a quadrant of the parking area. The plastic scintillation detectors are $7.6 \mathrm{~cm}$ ( 3 in.) wide by $3.8 \mathrm{~cm}$ ( 1.5 in.) thick and 91.4 cm (36 in.) long with a light pipe $12.7 \mathrm{~cm}$ (5 in.) long bonded to one end. Each detector cabinet also contains a preamplifier that transmits pulses to an amplifier located in an electronics cabinet. Each monitoring group has its own amplifier and high-yoltage power supply. The overhead detectors are a monitoring group, and each pair of underground detector cabinets containing four detectors is a monitoring group.

*Jomar Systems, Inc., 1143 18th Street, Los Alamos, NM 87544 (505) 662-9811.
The controller for the monitoring station, Jomar JNC-12, has four data channels, one for each group, and uses sequential probability ratio decision logic for each channel to minimize the monitoring time needed to meet detection sensitivity and false-alarm rate goals. This versatile controller has teletype input and output of operating parameters and monitoring information and also has vocal output capability. In particular, when the monitor is out of service from high or low background, the guard can be told vocally to monitor each vehicle with a hand-held monitor. The controller also is located in the air-conditioned electronics cabinet with the teletype and signal-conditioning electronics. Information, including vocal announcements, is trarssmitted to the guard through a remote information moujule located in the guard station. A similar module with status lamps is located outdoors near the vehicle being monitored.

The monitoring-station SNM sensitivity under worstcase conditions is listed in Table II. The minimum detectable quantities of ${ }^{60} \mathrm{Co}$ and ${ }^{137} \mathrm{Cs}$ transported in a minimum attenuating vehicle are one-third and twothirds of a microcurie, respectively, at $20 \mu \mathrm{R} / \mathrm{h}$ background intensity. Variations of the basic monitor having higher or lower sensitivity are possible. One highersensitivity version, proposed but not constructed, has additional detector groups located beside the parked vehicle. These detectors increase the monitor's sensitivity but are incrementally much less effective than the basic detector pattern. They would serve only to eliminate special problems.

The cost of the monitoring station is about $\$ 70,000$ for the fabricated and installed detection system and an additional $\$ 75,000$ for the concrete work, aluminum trench covers, cabinet and conduit installation, and canopy.

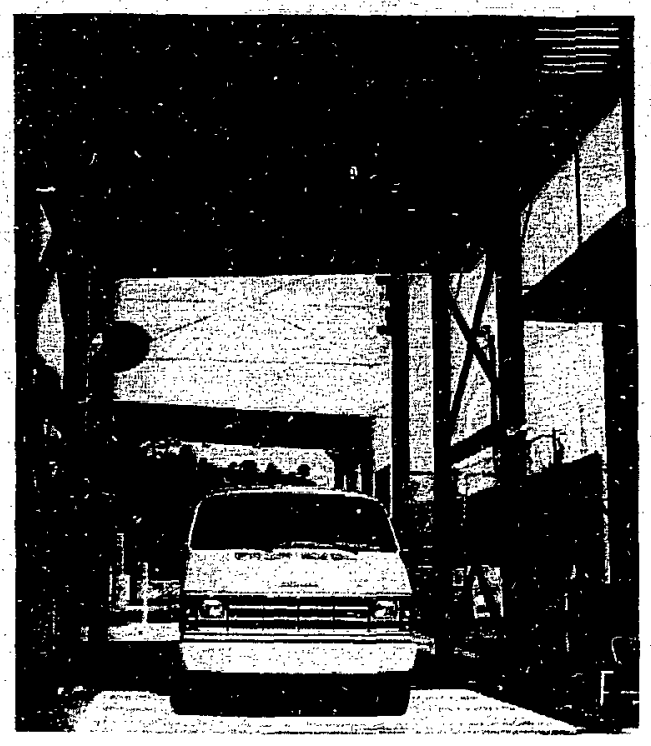




\section{NEUTRON VEHICLE SNM PORTAL MONITOR}

Although it is not yet commercially available, the Los Alamos neutron vehicle portal monitor exists as a welldeveloped prototype that is undergoing evaluation in routine operation. Each of two very large detector units,

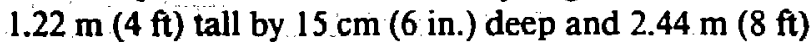
long, has aluminum-clad polyethylene walls forming a chamber that contains four ${ }^{3} \mathrm{He}$ proportional counters $5 \mathrm{~cm}$ ( 2 in.) in diameter by $183 \mathrm{~cm}$ (6 ft) long. Fissionspectrum neutrons from SNM are moderated in the polyethylene walls and then migrate to the proportional counters where they are detected. The counters are graphite lined to absorb electronegative gases that limit counter lifetime and have an absolute ${ }^{3} \mathrm{He}$ fill pressure of $400 \mathrm{kPa}$ atmospheres), giving them an intrinsic efficiency for thermal neutroris of about $92 \%$. The detector units were fabricated at Los Alamos using Reuter Stokes* nroportional counters. One of the detector units is positioned at each side of a roadway to form a portal.

The monitor's control unit uses a form of the sequential probability ratio decision method based on Poisson

*Reuter Stokes, 18530 South Miles Parkway, Cleveland, OH 44128, (216) 475-3434. counting statistics to accommodate very low neutron background intensity. The prototype control unit (JNC-17) was fabricated to a Los Alamos specification by Jomar Systems, Inc., ${ }^{*}$ and is housed in an airconditioned electronics cabinet located near one of the detectors. Vehicle sensors in the roadway inform the controller when to monitor. Otherwise, it continuously measures neutron background intensity. Operating parameters for the monitor are input by teletype, and operating information can be obtained by teletype printout.

Sensitivity of the monitor for detecting shielded plutonium at $8 \mathrm{~km} / \mathrm{h}$ under worst-case conditions is estimated to be as good as in the vehicle monitoring station where parking is required. Of course, the neutron portal does not sense gamma rays, so, unlike the monitoring station, its performance does not improve for unshielded plutonium. Our cost for materials, proportional counters, control unit, and signal conditioning electronics modules was $\$ 31,000$, exclusive of any machining or other labor costs. Commercial price for the monitor would likely be higher.

*Jomar Systems, Inc, 1143 18th Street, Los Alamos, NM 87544, (505) 662-9811:

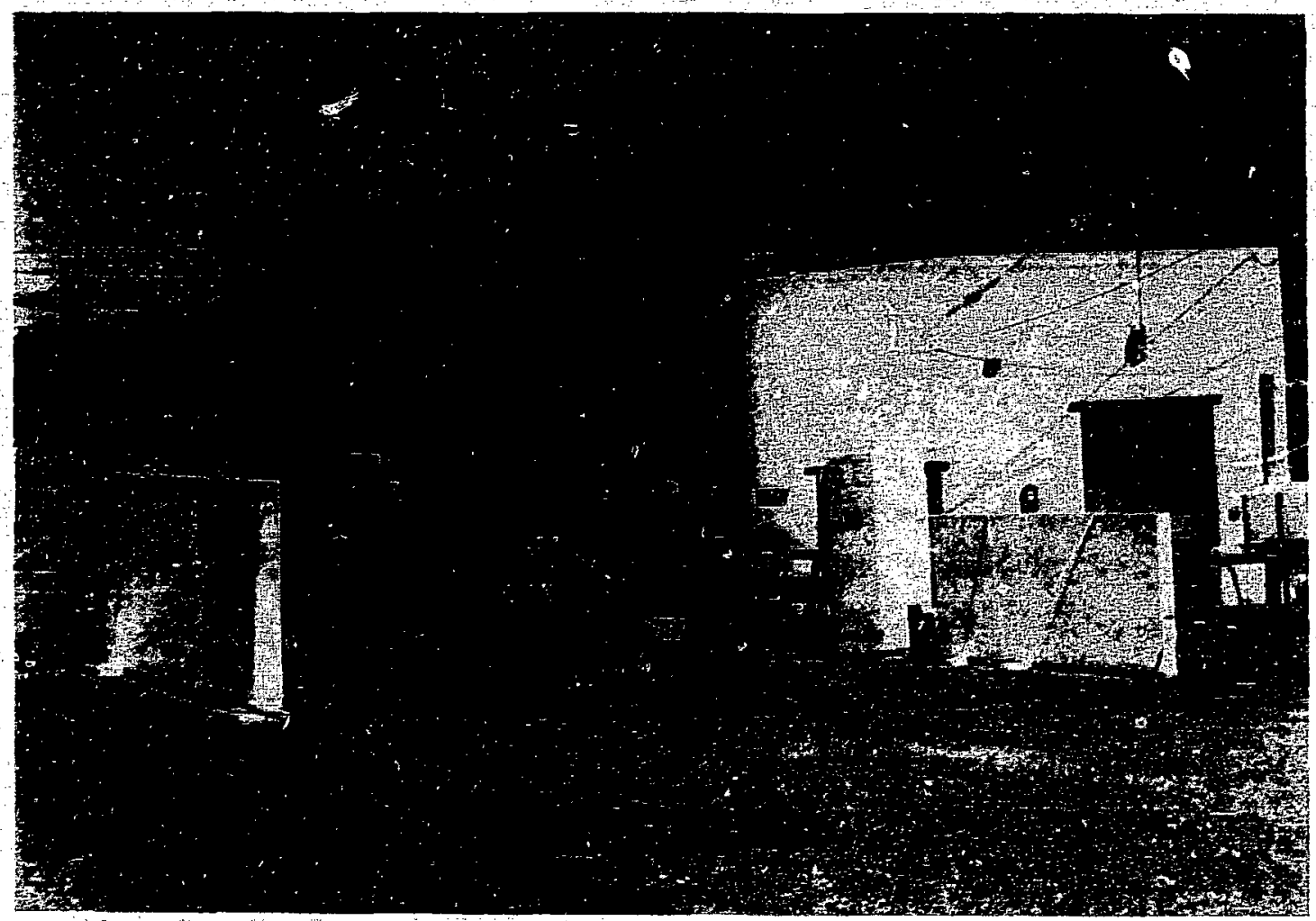




\section{BEFIC SAS 11 VEHICLE MONITOR}

A dual-purpose vehicle portal designed to detect both SNM in vehicles and gamma-ray contamination on vehicles, the BEFIC* SAS 11 vehicle portal monitor uses a single $\mathrm{NaI}(\mathrm{Tl})$ detector $7.6 \mathrm{~cm}$ (3 in.) in diameter by $7.6 \mathrm{~cm}(3 \mathrm{in}$.) tall on each side of a portal. A wallmounted cabinet contains the microprocessor control unit. All other electronic circuits are contained with the detectors in beacons, which are fiber glass cabinets sealed with gaskets for outdoor use. A microwave occupancy sensor notifies the microprocessor that monitoring is required.

*BEFIC, 89-93, rue des Alpes, SILIC 515, 94623 Rungis, France, (1) 687.25.16 - Telex: 202749.
Monitoring is continuous when a vehicle is present and uses a repeated 1 -s-long single-interval test to detect increased radiation intensity. Data from each detector are processed independently. BEFIC estimates the SAS- 11 sensitivity for the radioisotopes ${ }^{60} \mathrm{Co}$ and ${ }^{137} \mathrm{Cs}$ as 50 and $100 \mu \mathrm{Ci}$, respectively. These are minimum detectable quantities for $30-\mathrm{km} / \mathrm{h}$ passage speed, a $2-\mathrm{m}$ closest approach distance between source and detector, and a background intensity of $20 \mu \mathrm{R} / \mathrm{h}$.

This monitor has not been evaluated in this country, but a similar one having the same detectors in larger cabinets with additional detectors was evaluated at Los Alamos. That monitor displayed excellent craftsmanship in mechanical and electrical construction. Our evaluation results for that monitor are consistent with the sensitivity values quoted in the preceding paragraph. 


\section{ACKNOWLEDGMENTS}

I thank those members of the Los Alamos Advanced Nuclear Technology Group who from time to time have assisted me to develop and evaluate vehicle radiation monitors. Ken Coop did much of the prototype neutron vehicle portal development, and both he and Henry Atwater calculated detector efficiencies for alternative neutron detectors using Monte Carlo neutron transport codes. I credit both TSA Systems, Inc., and Jomar, Inc., with providing good ideas for improving the hardware and software that they supplied for Los Alamos developed radiation monitors.

\section{REFERENCES}

1. P. E. Fehlau, "An Applications Guide to Pedestrian SNM Monitors," Los Alamos National Laboratory report LA-10633-MS (February 1986).

2. P. E. Fehlau, C. Garcia, Jr., R. A. Payne, and E. R. Shunk, "Vehicle Monitors for Domestic Perimeter Safeguards," Los Alamos National Laboratory report LA-9633-MS (January 1983).

3. P. E. Fehlau, "Hand-Held Search Monitor for Special Nuclear Materials, User's Manual," Los Alamos National Laboratory publication LALP-84-15 (1984).

4. R. H. Augustson and T. D. Reilly, "Fundamentals of Passive Nondestructive Assay of Fissionable Material," Los Alamos National Scientific Laboratory report LA-5651-M (September 1974).

5. M. E. Anderson and J. F. Lemming, "Selected Measurement Data for Plutonium and Uranium," Mound Laboratory report MLM-3009 (November 1982).
6. P. E. Fehlau, J. C. Pratt, J. T. Markin, T. Scurry, Jr., "Smarter Radiation Monitors for Safeguards and Security," Nucl. Mater. Manage. XII (Proceedings Issue), 122 (1983).

7. P. E. Fehlau and G. S. Brunson, "Coping with Plastic Scintillators in Nuclear Safeguards," IEEE Trans. Nucl. Sci. NS-30, 158 (1983).

8. J. W. Tape, D. A. Close, and R. B. Waiton, "Total Room Holdup of Plutonium Measured with a Large-Area Neutron Detector," Nucl. Mater. Manage. V. (Fall Issue), 533 (1976).

9. L. V. East and R. B. Walton, "Polyethylene Moderated ${ }^{3} \mathrm{He}$ Neutron Detectors," Nucl. Instrum. Methods 72, 161-166 (1969).

10. P. E. Fehlau, K. L. Coop, and J. T. Markin, "Application of Wald's Sequential Probability Ratio Test to Nuclear Materials Control," Proceedings of ESARDA/INMM Joint Specialists Meeting, Ispra, Italy, September 10-12, 1984, M. Franklin, L. Stanchi, and J. T. Markin, Eds. (Commission of the European Communities, Joint Research Center, Ispra, Italy).

11. P. E Fehlau, K L. Coop, and K. V. Nixon, "Sequential Probability Ratio Controllers for Safeguards Radiation Monitors," Proceedings of the 6th Annual ESARDA Symposium on Safeguards and Nuclear Materials Management, Venice, Italy, May 1984, L. Stanchi, Ed. (Commission of the European Communities, Joint Research Center, Ispra, Italy).

12. P. E. Fehlau, "Gamma-Ray Detectors for Intelligent, Hand-Held Radiation Monitors, ${ }^{n}$ IEEE Trans. Nucl. Sci. NS-31, 664 (1984).

13. Sandia Laboratories Nuclear Security Systems Group, "Entry Control Systems Handbook," Sandia National Laboratories report SAND 77-1033 (September 1978). 